\title{
COVID 19 - Possible interrelations with respiratory comorbidities caused by occupational exposure to various hazardous bioaerosols. Part II. Clinical course, diagnostics, treatment and prevention
}

\author{
Barbara Mackiewicz ${ }^{1, A-E \oplus}$, Marta Kinga Lemieszek ${ }^{2, A-E \oplus}$, Jacek Dutkiewicz, \\ ${ }^{1}$ Department of Pneumonology, Oncology and Allergology, Medical University, Lublin, Poland \\ ${ }^{2}$ Department of Medical Biology, Institute of Rural Health, Lublin, Poland \\ ${ }^{3}$ Department of Biological Health Hazards and Parasitology, Institute of Rural Health, Lublin, Poland \\ A - Research concept and design, B - Collection and/or assembly of data, C - Data analysis and interpretation, \\ $D$ - Writing the article, E - Critical revision of the article, F - Final approval of article
}

\begin{abstract}
Mackiewicz B, Lemieszek MK, Dutkiewicz J. COVID 19 - Possible interrelations with respiratory comorbidities caused by occupational exposure to various hazardous bioaerosols. Part II. Clinical course, diagnostics, treatment and prevention. Ann Agric Environ Med. $2021 ; 28(1): 27-43$. doi: $10.26444 /$ aaem/133896
\end{abstract}

\begin{abstract}
Introduction and objective. The course of COVID-19 caused by the SARS-CoV-2 may be aggravated by bioaerosols containing other viruses, bacteria, and fungi, occurring mainly in the occupational environment. Hence, the diagnostics and treatment of COVID-19 should address such a possibility in the anamnesis, treatment and final recommendations for avoiding of adverse exposure.

Abbreviated description of the state of knowledge. As SARS-CoV-2 attacks primarily the respiratory system and the severe manifestation of COVID-19 is interstitial pneumonia, diagnostics should include the following clinical and laboratory examinations: chest X-ray; high resolution computed tomography (HRCT); pulmonary function tests; arterial-blood gas test; genetic tests for the presence of SARS-CoV-2, in the future with the use of highly specific and sensitive nano-based biosensors; tests for the presence of specific immunity against the antigens of microorganisms causing other infectious or allergic pulmonary diseases (in the case of anamnestic indications). Because an universally accepted treatment for COVID-19 does not exist, the hitherto prescribed antiviral and immune-modulating drugs should be used be with caution. In many cases, a better alternative could be a safe supportive therapy, such as supplementation of the diet with probiotics, prebiotics, vitamins and microelements.

Conclusions. The most important preventive measures against COVID-19 should include: vaccination; the use of filter or surgical masks; disinfection and sterilization; maintaining of well-functioning ventilation and air conditioning systems; reduction of the community air pollution which has been identified as an important factor increasing the COVID-19 severity. In the choice of preventive measures, the above should be considered for their potential efficacy against other bioaerosols as potential disease-aggravating agents.
\end{abstract}

Key words

SARS-CoV-2, COVID-19, clinical course, diagnostics, therapy, prevention, comorbidities, bioaerosols, hypersensitivity pneumonitis, ODTS

\section{INTRODUCTION}

COVID-19 and comorbidities. In December 2019, a true 'Resident Evil' emerged in mysterious circumstances from a 'wet market' in Wuhan, China. This was an incredibly contagious coronavirus, one of the most dangerous pathogens in human history. This virus, named shortly thereafter 'SARS-CoV-2' causes the disease named 'COVID-19' that by 27 February 2021 had infected worldwide over 114 million people, caused the death over 2.5 million, and totally devastated social and economic life in most countries $[1,2]$.

Knowledge about the interrelations between this 'new' disease, and 'old' diseases that trouble humans for centuries,

Address for correspondence: Barbara Mackiewicz, Department of Pneumonology, Oncology and Allergology, Medical University, Lublin, Jaczewskiego 8, 20-954 Lublin, Poland

E-mail: b.mack@wp.pl

Received: 22.02.2021; accepted: 03.03.2021; first published: 16.03.2021 is very important as it has been evidenced that such conditions as hypertension, diabetes mellitus, cardiovascular diseases, and obesity $[1,3]$ occur commonly as comorbidities among COVID-19 patients and aggravate the course of the disease. As SARS-CoV-2 attacks primarily the respiratory system and the severe manifestation of COVID-19 is interstitial pneumonia $[1,3,4]$, the interrelations between this disease and other respiratory diseases are of special interest.

A large part of human respiratory diseases is evoked by viable particles suspended in the air, forming so-called 'bioaerosols'. They comprise viruses, bacteria, fungi and their products, mostly attached to dust particles or droplets, as well as particles of plant and animal origin. Depending on species, the inhaling of bioaerosols may be a cause of infectious diseases (such as COVID-19 itself after inhaling SARS-CoV-2), as well as of allergic or immunotoxic diseases. Diseases caused by bioaerosols, such as hypersensitivity pneumonitis (HP), organic dust toxic syndrome (ODTS), 
or byssinosis, are usually caused by occupational exposure. Nevertheless, there are some diseases, such as BuildingRelated Disease (BRD) or humidifier fever, which occur more often after exposure taking place in the living environment $[5,6,7,8]$.

\section{Diagnostics recognizing the role of bioaerosols as factors} exacerbating the course of COVID-19. There are strong indications presented by us in Part I of this review article [8] that infection with SARS-CoV-2 may exacerbate preexisting infectious, allergenic, or immunotoxic respiratory diseases caused by other biological agents that are present in bioaerosols occurring in the occupational or living environment. Conversely, other airborne viruses, bacteria, fungi, and their products having infectious, allergenic, and/ or immunotoxic properties, as well as allergenic particles of plants and animals, may aggravate the course of COVID-19 which otherwise would be mild or symptomless. Hence, the detailed anamnesis focusing on the working and living environment of a patient with COVID-19 and his/her possible exposure to bioaerosols is crucial for prognosis and treatment of the disease, as well as for making post-disease recommendations to the patient, such as avoiding some work, contacts or situations. In each patient with diagnosed COVID-19, it is very important to perform the following clinical and laboratory examinations which could be helpful, not only for confirming the primary diagnosis, but also for the detection of co-existing pulmonary diseases caused by other bioaerosols, especially when the anamnesis indicated such a possibility:

- chest X-ray;

- high resolution computed tomography (HRCT);

- pulmonary function tests comprising: spirometric measurements (FVC, FEV,$F_{1}$ \%FVC, TLC, RV), measurements of diffusion lung capacity for carbon monoxide (DLCO), and body plethysmography;

- arterial-blood gas test;

- blood morphology;

- tests for the presence of inflammatory proteins (cytokines, CRP);

- tests for the presence of specific immunity against the antigens of viruses and/or bacteria causing infectious pulmonary diseases (in the case of anamnestic indications);

- tests for the presence of specific immunity against the antigens of bacteria and fungi causing allergic pulmonary diseases (in the case of anamnestic indications) $[9,10,11]$.

Therapy. Until recently, there did not exist a single globallyaccepted treatment for COVID-19 [12, 13, 14, 15]. Among the applied therapeutics, the most common are: antiviral drugs (such as Remdesivir), anti-inflammatory drugs (such as corticosteroids), immunomodulators (such as interferons, monoclonal antibodies, convalescent plasma), and supportive therapy such as supplementation of the diet with probiotics, prebiotics, vitamins and microelements, which deserve a special attention $[1,3,16,17,18,19,20]$.

Prevention. Prophylactic measures against COVID-19 that could be applied at the personal and institutional level include: the use of the filter masks in occupations associated with the risk of exposure to SARS-CoV-2 and the use of the surgical mask in public places; disinfection and sterilization; and the maintaining of well-functioning ventilation and air conditioning systems. The measures that could be applied at the governmental level include: vaccination, total or partial 'lockdown', a ban on gatherings, imposing an obligatory quarantine for infected and endangered persons, and reduction of the community air pollution. These measures should protect not only against SARS-CoV-2, but also against other biological, chemical, and physical pollutants of the air that may aggravate the course of COVID-19 [16, 21, 22, 23, 24].

Part I of this article focused on the theoretical assessment of possible comorbid interrelations of COVID-19 with occupational diseases caused by exposure to various bioaerosols, and gave the detailed characteristics of these diseases [8]. This part is intended as a practical aid for medical staff combating COVID-19, concentrating mainly on the more detailed characteristics of the clinical course, diagnostics, therapy and prevention of COVID-19 itself and, to a lesser extent, on the characteristics of hypersensitivity pneumonitis (HP) as a clinical entity that can mimic the severe form of COVID-19.

\section{CLINICAL COURSE}

Clinical course of COVID-19. COVID-19 is a disease caused by infection with the SARS-CoV-2 virus, which develops within 2-14 days after infection, most frequently during 4-5 days. The source of infection may be a symptomatic patient, a patient during the period of incubation of the virus, or an infected asymptomatic patient. Infectiousness most probably occurs 1-2 days prior to the occurrence of symptoms, and lasts for 7-12 days; however, excretion of the virus in exhaled air may persist even up to 14 days after infection. The virus present in mucus discharge from the nose, mouth, and eyes of the infected person is transmitted via the droplet route (coughing, sneezing). The virus may settle on various surfaces and survive for many days in conducive conditions (metal and smooth surfaces, low temperatures) [25]. The mean age of the infected patients is 55.5, and the disease affects children, adults, and elderly patients [26]. In children, the infection is most often asymptomatic or mild, and complete recovery is achieved faster. The infection is more common in males (59-68\% of patients) [27], similar to patients affected with hypersensitivity pneumonitis (HP).

The disease caused by the SARS-CoV-2 virus may take a mild, moderate, or severe course [28]. The clinical manifestation of the illness has not yet been fully defined because its course may be asymptomatic, which has been observed even in $30 \%$ of patients [29], and occurred symptoms may range from mild to very severe. In $80 \%$ of patients, the disease has a mild course, and the most frequent symptoms of COVID-19 are cough occurring in $61-76 \%$ of patients, sub-febrile temperatures or fever in $72-98.6 \%$ of patients, and fatigue. Less commonly occur headache and dizziness, chills, loss of smell and/or taste, shortness of breath, muscle aches and whole-body pain, while more rarely diarrhea, vomiting or nausea [30]. People with a mild course of the disease may be treated at home, and the symptoms usually resolve within 7-14 days. Symptomatic therapy and hydration are used for treatment.

According to the World Health Organization (WHO), severe COVID-19 disease is a condition concerning an adult with clinical signs of pneumonia (fever, dyspnea, cough, 
increased respiratory rate) accompanied by one of the following symptoms: respiratory failure, respiratory rate $>$ 30 per minute, or saturation below $90 \%$. Severe COVID-19 usually starts approximately 7-8 days after the onset of symptoms. In laboratory tests, in the majority of patients are observed lymphopenia ( $80 \%$ and over), thrombocytopenia, normal white blood cells, elevated values of AST, ALT, total bilirubin, D-dimers, IL-6, IL-10 and lactate dehydrogenase, while the markers of inflammation (CRP and procalcitonin) are usually low. Patients with severe COVID-19 fulfill the criteria for acute respiratory distress syndrome (ARDS), many of whom have thromboembolic complications as well as neurological disorders. In the mentioned cases, the disease may lead to acute heart, renal and hepatic failure, rhabdomyolysis, coagulopathy and shock. In a large group of patients with COVID-19, $81 \%$ had a mild course of the disease, $14 \%$ developed the severe disease, while $5 \%$ were in a critical condition. Mortality among critically ill patients was $49 \%$ [31]. The most important risk factor of the severe course of the disease or death is age, and the risk increases with each subsequent decade. At the risk of a severe course of COVID-19 are also patients with chronic cardiovascular diseases, diabetes mellitus, obesity (BMI $>30)$, with immunosuppression as a result of the primary disease or those who receive immunosuppressive therapy, as well as patients suffering from moderate to severe asthma.

It is probable that the social determinants of health also exert an important effect on the risk of severe disease [32]. Patients with severe COVID-19 should receive treatment in highly specialized hospital wards, with the possibility to apply oxygen therapy, non-invasive mechanical ventilation and, if necessary, intratracheal intubation and mechanical ventilation [33]. In the bulletin published by the American College of Cardiology, mortality rates were the highest in the case of cardiovascular diseases (10.5\%), followed by diabetes mellitus (7.3\%), COPD (6.3\%), hypertension (6\%), and neoplastic disease (5.6\%). Some markers may also indicate an unfavourable course of the disease, including: elevated levels of D-dimers, CRP, lactate dehydrogenase, cardiac troponin, and IL-5, IL-6, IL-8, IL-10, IL-11. In patients with COVID-19, coagulation disorders and large vessel strokes were described, which evidences damage to the vascular endothelium of the main regulator of thrombosis and haemostasis by SARS-CoV-2. Additionally, changes in other coagulation factors indicate the development of hypercoagulability and, in consequence, an increased risk of thrombosis [34]. Diagnostic imaging modalities, chest X-ray and CT, allowing determination of the extent of inflammatory changes in the pulmonary parenchyma, such as bilateral 'frosted-glass-like' opacities, changes to the 'paving stones' type, traction bronchiectasis, dilation of the pulmonary artery, which indicates pulmonary hypertension, are also prognostic factors of a severe course and mortality in COVID-19 [35].

A study by Sanchez-Gonzales et al. [4], published in July 2020 , posed the hypothesis that SARS-CoV-2 may act as a trigger and substrate of severe hypersensitivity pneumonitis (HP) with immune dysregulation, especially in a genetically susceptible patient. In both diseases, e.g. COVID-19 and HP, the cytokine storm, activation of macrophages, thrombosis, ARDS and pulmonary fibrosis may be observed, often leading to death. A striking similarity was observed between the clinical symptoms of the severe form of COVID-19 and the severe form of HP. Similar observations were reported by Song and Shin [36] who indicated that COVID-19 may be defined as a hypersensitivity reaction induced by SARSCoV-2 infection - hypersensitivity pneumonitis (HP). In the pathogenesis participate: monocytes, macrophages, eosinophils, neutrophils, and lymphocytes which cause the cytokine storm (IL-1 $\beta$, IL-6, IL-12, IL-17, IFN- $\gamma$, TNF- $\alpha$ ), leading to excessive inflammation and extracellular spread of the virus. Prednisolone is the most effective drug in HP, as well as in COVID-19 by inhibiting cytokines (IL-1, IL-6, TNF- $\alpha$ ); there are strong indications that SARS-CoV-2 may initiate or exacerbate the symptoms of HP.

Clinical course of hypersensitivity pneumonitis (HP). Hypersensitivity pneumonitis is an inflammatory interstitial lung disease developing as a result of repeated exposure to allergens in organic dust or fine inorganic particles. In the background of the pathogenesis of HP lies type III of immune reaction with the production of IgG class immunoglobulins, which after binding to the antigen form immune complexes. These immune complexes are capable of activation of the complement cascade, resulting in the activation of macrophages and release of cytokines, which induce the inflow of neutrophils and macrophages into the interstitial tissue, and subsequently, of lymphocytes, the amount of which in bronchoalveolar lavage (BALF) may reach up to $60-90 \%$ of cell composition of BALF and persists for a long time, even up to several years after cessation of exposure. These mechanisms are the cytokine storm, i.e. systemic inflammatory response caused by unnaturally stimulated cells of the immune system, during which there occurs uncontrolled secretion of a high amount of pro-inflammatory proteins called cytokines, similar to pathomechanisms of COVID-19.

At present, an acute and a chronic form of the HP are distinguished. In the acute form, which develops for several hours after massive exposure to allergen, there occur symptoms that mimic respiratory tract infection: fever, chills, dry cough, shortness of breath, headache, muscle pain, and sometimes nausea. These complaints usually resolve spontaneously 2448 hours after exposure to the harmful agent(s). Avoidance of the antigen or use of a glucocorticosteroid in cases with extremely acute or prolonged symptoms is sufficient therapeutic management. The chronic form of HP develops insidiously, for a long time, without characteristic symptoms, leading to irreversible interstitial pulmonary fibrosis and symptoms of respiratory failure. It remains unknown why, among such a considerable number of people exposed, only a slight percentage of them become ill, and why the disease may take a chronic form with an unfavourable prognosis [11]. Creamer and Barratt [37] presented a review of the current data concerning prognostic factors of the progression and survival with chronic HP. The researchers reported that older age is associated with increased mortality due to hypersensitivity pneumonitis, similar to COVID-19. Also, the male gender is associated with higher mortality rates. Identification of an environmental antigen, and consequently, the possibility to avoid or decrease exposure to the antigen had no significant effect on survival with HP, contrary to what was believed that avoidance of the antigen reduces the probability of occurrence of a chronic form of the disease. However, it was observed that the intensity of exposure may exert a significant effect on the progression of HP. There are many conflicting data concerning the effect of exposure to 
an environmental antigen and the course of the disease; nevertheless, it seems that the greatest difficulty is in the confirmation of whether it is actually possible to avoid the allergen. Similarly, it is difficult to establish an ambiguous position concerning tobacco smoking and its effect on the course and mortality in HP. There are data that indicate that an acute form of HP more often occurs in non-smokers, while the development of a chronic form and fibrosis is more frequently observed in smokers [38]. Similarly, in COVID-19 it was demonstrated that tobacco smoking may decrease the susceptibility to infection with SARS-CoV-2 by modification of expression of ACE2 receptors [39, 40]; however, when it comes to the severe form of COVID-19 with interstitial pneumonia, the course is considerably more severe in smokers. The presence of concomitant diseases deteriorates the prognosis in HP as well as in COVID-19.

\section{DIAGNOSTICS}

Clinical diagnostics of COVID-19. Patients who are suspected of SARS-CoV-2 infection should be diagnosed. Those patients present at least one of the following symptoms: cough, fever, dyspnea, loss of smell or taste, with a rapid onset of the disease, and patients who within the period of 14 days prior to the occurrence of the symptoms had a close contact with a person infected with SARS-CoV-2, as well as patients who had a contact with the virus carrier, regardless of whether or not they had the mentioned symptoms. Quick and precise diagnosis is of crucial importance for the implementation of appropriate treatment and provision of isolation. The diagnostics of COVID-19 is based on detection of the genetic material of the virus, and detection of viral protein antigens in the nasopharyngeal swab, as well as the determination of the concentration of anti-SARS$\mathrm{CoV}-2$ antigens in venous blood. The 'gold standard' in the diagnostics of COVID-19, recommended by the WHO, is the detection of nucleic acids, especially the real-time reverse transcription-polymerase chain reaction (RT-PCR) assay. This is the polymerase chain reaction in which the first step is performed by reverse transcriptase, in real-time, where the matrix is the RNA particle. Although the test is highly specific, sometimes it may provide false-negative results due to contamination of the specimen or technical errors while performing the test. A positive result is present during the occurrence of the symptoms and several days after, and sometimes it may persist even up to 6 weeks in convalescents. This test requires laboratory analysis with the use of specialist equipment, and the waiting time for the result is from several to 24 hours. Antigen-based assays allow the detection of SARS-CoV-2 spike proteins, the receptor-binding domain or viral nucleoprotein receptors. The advantage of this test is obtaining the result quickly, its high specificity, and relatively low cost. Unfortunately, the low sensitivity of the assay (80$90 \%$ ) does not allow the exclusion of infection when the result is negative. Serologic tests consist of finding suitable viral antigens, in the case of anti-SARS-CoV-2 antigens, against which antibodies are detected - spike glycoprotein (S) and nucleocapsid phosphoprotein (N) [12]. Serologic tests for the detection of antibodies against SARS-CoV-2 in the patient's blood include: ELISA, lateral flow assay (FLA), and virus neutralization tests. The IgG and IgM class antibodies are detected. IgM antibodies are detected within the first several weeks, while IgG antibodies are detected later. Detection of antibodies confirms past contact with the virus; unfortunately, the absence of antibodies does not provide a basis for the exclusion of past infection [41].

The role of imaging tests in the diagnostics of infection with SARS-CoV-2. In asymptomatic forms or with mild symptoms from the respiratory system, imaging diagnostics is unnecessary. However, when there are clinical indications, such as persistent cough, fever, shortness of breath, or deterioration of the general condition, the performance of a chest X-ray is recommended as the first line examination. When the intensity of changes in the lungs is low, a chest $\mathrm{X}$-ray may provide a false-negative result; nevertheless, this examination is simple, cheap, and possible to perform using portable equipment, also in intubated and mechanically ventilated patients. Any of the single features of pneumonia caused by COVID-19 in the chest radiological image is neither specific nor diagnostic, but there may occur a combination of multifocal changes in the peripheral lungs, opacity and/ or consolidation, which are most often bilateral.

In the chest radiograph in patients with COVID-19 may be observed peripheral horizontal opacifications, or reticular pattern, which could be described as linear opacifications accompanying ground-glass images [42]. Computed tomography $(\mathrm{CT})$ is a more accurate and precise examination. Early diagnosis is of key importance in the treatment and control of the course of COVID-19. According to preliminary reports, CT has a relatively high sensitivity in diagnosing COVID-19, which is of great importance in the situation when in more than $80 \%$ of patients there are abnormalities in the lungs, and radiologic changes often precede clinical symptoms [43]. Chest imaging plays an important role in the detection of viral lung infection, assessment of the scope of the disease and its monitoring. Zhang et. al. [44] recommend the performance of chest CT in all patients with body temperature $>37.3^{\circ} \mathrm{C}$ and lymphocyte level $<1100 / \mu \mathrm{L}$. Guan et al. [45] reported that in 840 from among 975 patients (86.2\%) the following abnormalities in the chest CT were observed:

- ground-glass opacity - 505/975 patients;

- local patchy shadowing - 409/975 patients;

- bilateral patchy shadowing - 509/975 patients;

- interstitial abnormalities (reticular septal thickening) 143/975 patients.

Most often, bilateral occurrence of abnormalities is observed in CT in patients with COVID-19, the changes are multifocal, with mainly peripheral distribution, most often the lower lobes of the lungs are affected; usually pleural effusion, pulmonary nodules, lymphadenopathy, and disintegration are not observed. Changes occur of the type of ground-glass opacity, with consolidation areas, thickening of the interlobular and mediastinal septa, changes to the type of 'paving stones', traction bronchiectasis, and dilated vessels within the parenchyma consolidation [46]. In order to evaluate changes in COVID-19, it is sufficient to perform chest high-resolution CT (HRCT) without contrast. This is a non-invasive examination, safe for the patient, the dose of radiation is not high, and it is characterized by high sensitivity in the detection of inflammatory changes (Figs. 1-2). The CT image is non-specific for SARS-CoV-2, the same or a similar image may be observed in other inflammations, including 


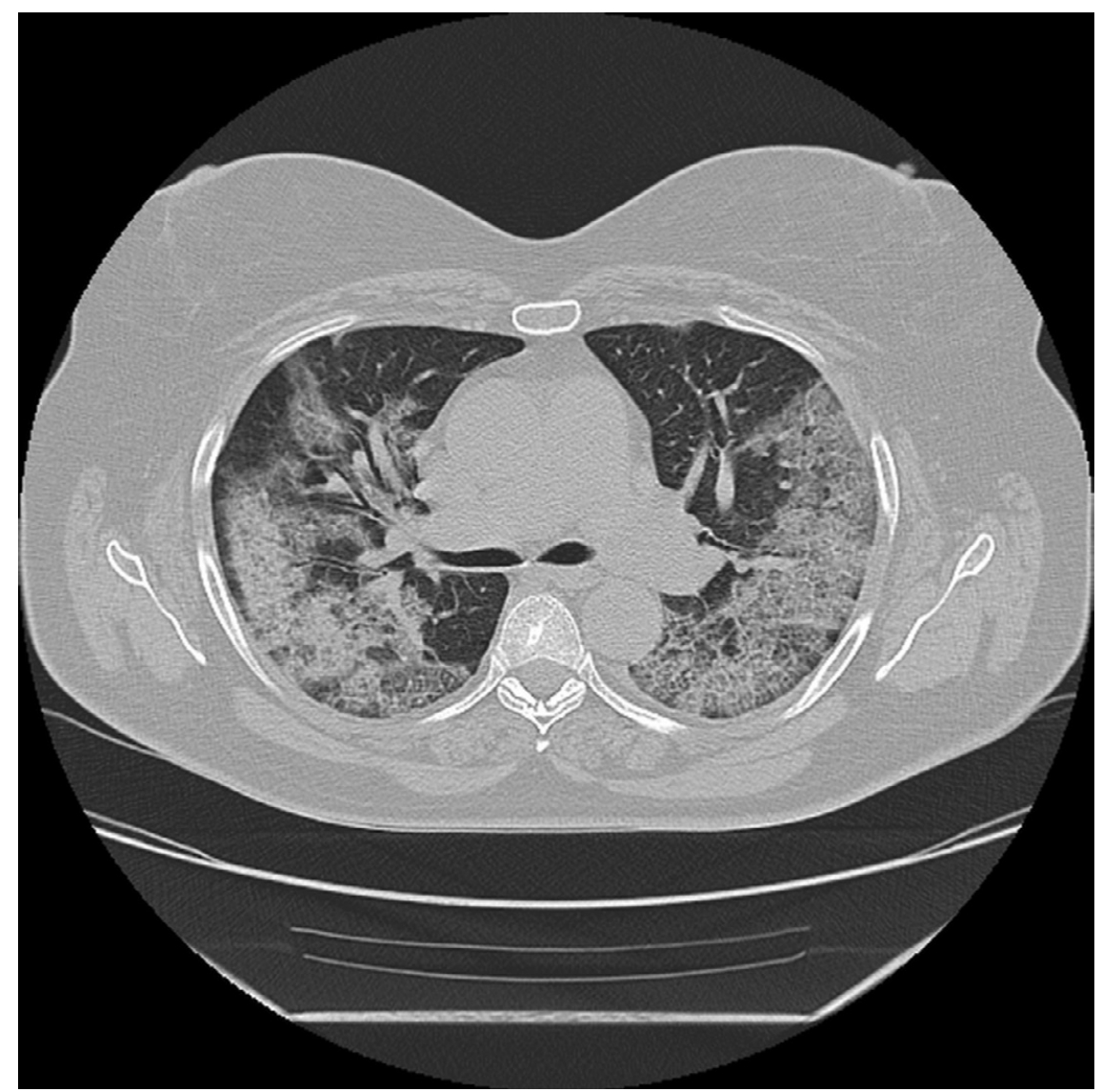

Figure 1. HRCT of patient during COVID-19, day 5 of illness. Visible multifocal, bilateral, peripheral ground-glass pattern. Source: Own collection, B. M.

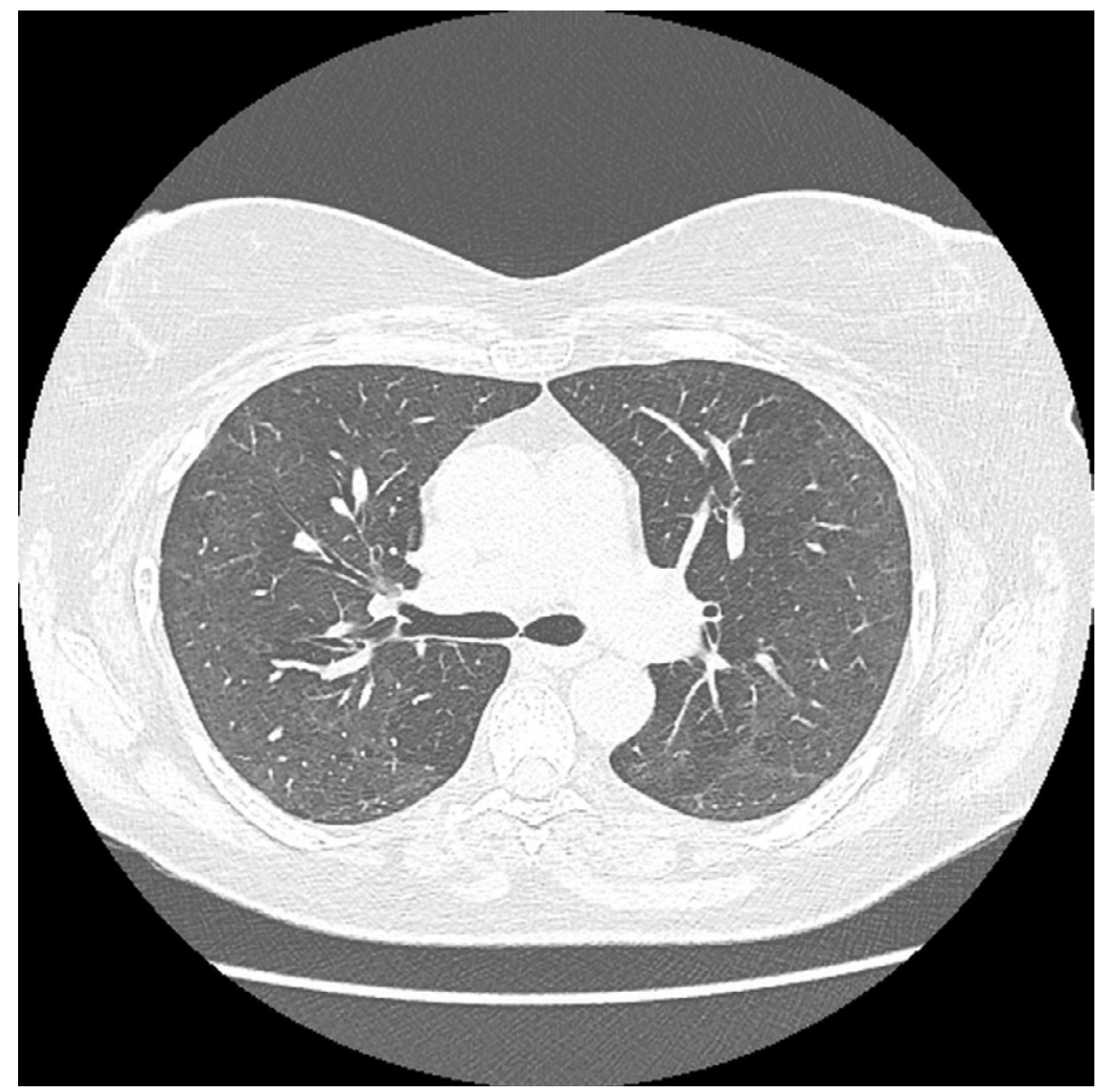

Figure 2. HRCT of the same patient 3 months after COVID-19. Almost complete regression of changes visible. Source: Own collection, B. M. 
cryptogenic organizing pneumonia (COP), in inflammation caused by other viruses, in pneumocystodosis, or in acute toxic lung injury. However, CT is an important method in the assessment of the extent of COVID-19, its monitoring and planning therapeutic management and patient care [47].

The ultrasound imaging (USG) technique is also worth mentioning in diagnosing lung abnormalities in the course of SARS-CoV-2 infection. USG is a commonly available, cheap examination, which can be performed at a patient's bedside, and does not expose the patient to X-ray radiation. In a retrospective analysis, Huang et al. [48] evaluated clinical data and the results of lung ultrasound examinations. The researchers found that pulmonary changes in the course of COVID-19 produce characteristic images in USG examination, such as: the thickening and an irregular outline of the pleura, B-lines with variable arrangements - from single to confluent, multifocal consolidations involving the lung parenchyma, often with an aerial bronchogram, as well as A-lines occurring in the recovery phase. The intensity of changes depends on the stage of the disease. While comparing CT and ultrasound images, Huang et al. [48] observed that both types of images were highly coherent; however, CT showed clearer and more complete pulmonary abnormalities. Thus, lung USG may be used as a supplementary method, but cannot replace CT of the chest.

Adaptation of new technologies for detection of SARSCoV-2. The marked progress in nanotechnology offers a possibility to design highly specific and sensitive nano-based biosensors to improve the present diagnostics by quick and reliable identification of the infection with SARS-CoV-2 and/or immunological response to the invading virus. Moreover, the use of nanoparticle-based markers can enable the study of the mechanism by which viruses infect host cells. Among a variety of nanomaterials that could be used for virus detection, gold nanoparticles and graphene seem the most promising $[41,49]$.

Acquah et al. [50] have recently proposed the introduction of 'theranostics' into the strategy for combatting COVID-19, based on the successive application of two engineered radioactive oligonucleotide molecules called 'aptamers', of which the first fulfills the diagnostic, while the second the therapeutic function by targeting and cleaving the identified viral molecule. This strategy had been successfully used in fighting other viral diseases, and the authors supposed the same for COVID-19.

Clinical diagnostics of hypersensitivity pneumonitis. In the diagnosis of HP, a specific interview should be considered, aimed at confirmation of the relationship between exposure to organic dust and the occurrence of the symptoms of the disease, clinical image, laboratory tests, and imaging tests (chest radiograph and high resolution computed tomography - HRCT), assessment of the function of the respiratory system, bronchofiberoscopy with bronchoalveolar lavage, and histopathologic evaluation of a sample from the lung tissue collected by transbronchial lung biopsy or surgical biopsy. Determination of precipitins and/or total IgG antibodies by immunodiffusion, immunoelectrophoresis, or ELISA assay allows confirmation of the presence of precipitins against environmental antigens in serum. Although the examination confirms the exposure, it does not provide a basis for the diagnosis of HP because specific IgG is observed in $40-50 \%$ of those exposed who do not develop the disease, while in many cases of bird fancier's lung disease the results of the tests are negative, despite evident features of HP. In the chest X-ray, the image depends on the clinical picture. In an acute image, bilateral, fine-spotted and merging parenchymal changes may be found, occurring mainly in the central and lower fields of the lung. In high-resolution CT (HRCT) there occur fine, weakly enhancing nodules, creating the image of miliary spreading or uniform opacities, so-called ground-glass (Figs. 3-4). In the chronic form, dominate reticular opacities, fibrosis with honeycombing and features of emphysema. The abnormalities usually concern the upper and central lung fields, are located in the subpleural areas, are of a fixed character, frequently progressing [51]. Functional examination of the respiratory system in hypersensitivity pneumonitis reveals primarily the restrictive ventilatory disorders. The most characteristic is a decrease in the diffusing capacity of the lungs for carbon monoxide (decrease in DLCO).

Challenge tests with environmental allergens are aimed at the indication of the relationship between exposure and occurring symptoms. A controlled form of the test consists of the inhalation by a patient of a solution containing the antigen, starting from minimum concentrations. The test is considered as positive when after inhalation of the antigen in the target amount of $20 \mu \mathrm{g} / \mathrm{ml}$, an increase in ventilation is observed by a minimum of $15 \%$, an increase in the respiration rate by $25 \%$, a decrease in FVC by $15 \%$, an increase in the leukocyte count by $2,500 / \mathrm{mm}^{3}$ accompanied by a decrease in lymphocytes by $500 / \mathrm{mm}^{3}$, and elevation of the body temperature $>37.2^{\circ} \mathrm{C}$. The examination should be performed only in exceptional situations under the supervision of a specialist. Assessment of the fluid from bronchoalveolar lavage shows lymphocytosis in BALF $>40 \%$, and according to some- more than $50 \%$. An increase in the percentage of lymphocytes $\mathrm{CD} 8+$ with a decrease in lymphocytes CD4+ may be helpful in differential diagnostics. Histopathological tissue examination taken from transbronchial biopsy shows the presence of lymphocytic infiltrations with the formation of the granulomas and bands of connective tissue. After collection of the specimen by open surgical biopsy, the assessment is considerably more precise. Infiltrates of lymphocytes and plasma cells may be observed, and in the majority of cases the granulomas composed from epithelial and Langhans giant cells, or foreign body granulomas, abnormalities of the type of cryptogenic organizing pneumonia and changes of bronchiolitis obliterans type, while in chronic cases - fibrosis. Nevertheless, considering the high invasiveness of surgical biopsy, and the possibility of the occurrence of serious postprocedure complications (functional impairment of the patient, acute exacerbation of ILD, bleeding, and mortality risk), the use of this method could be recommended only as an exception, in cases which are difficult to diagnose $[10,11]$.

Summing up, it may be noted that medical history taking, the radiological image of changes in the lungs showing interstitial pneumonia with the use of HRCT, as well as the identification of the triggering agent play an important role in the diagnostics of both HP and COVID-19.

Diagnostics of organic dust toxic syndrome (ODTS). This toxic syndrome caused by the inhalation of organic dust, also called inhalation fever, grain fever or pulmonary mycotoxicosis, is characterized by the occurrence of acute symptoms, such as: sub-febrile temperatures or classic fever with chills, dry throat, headaches, osteoarticular pain, 


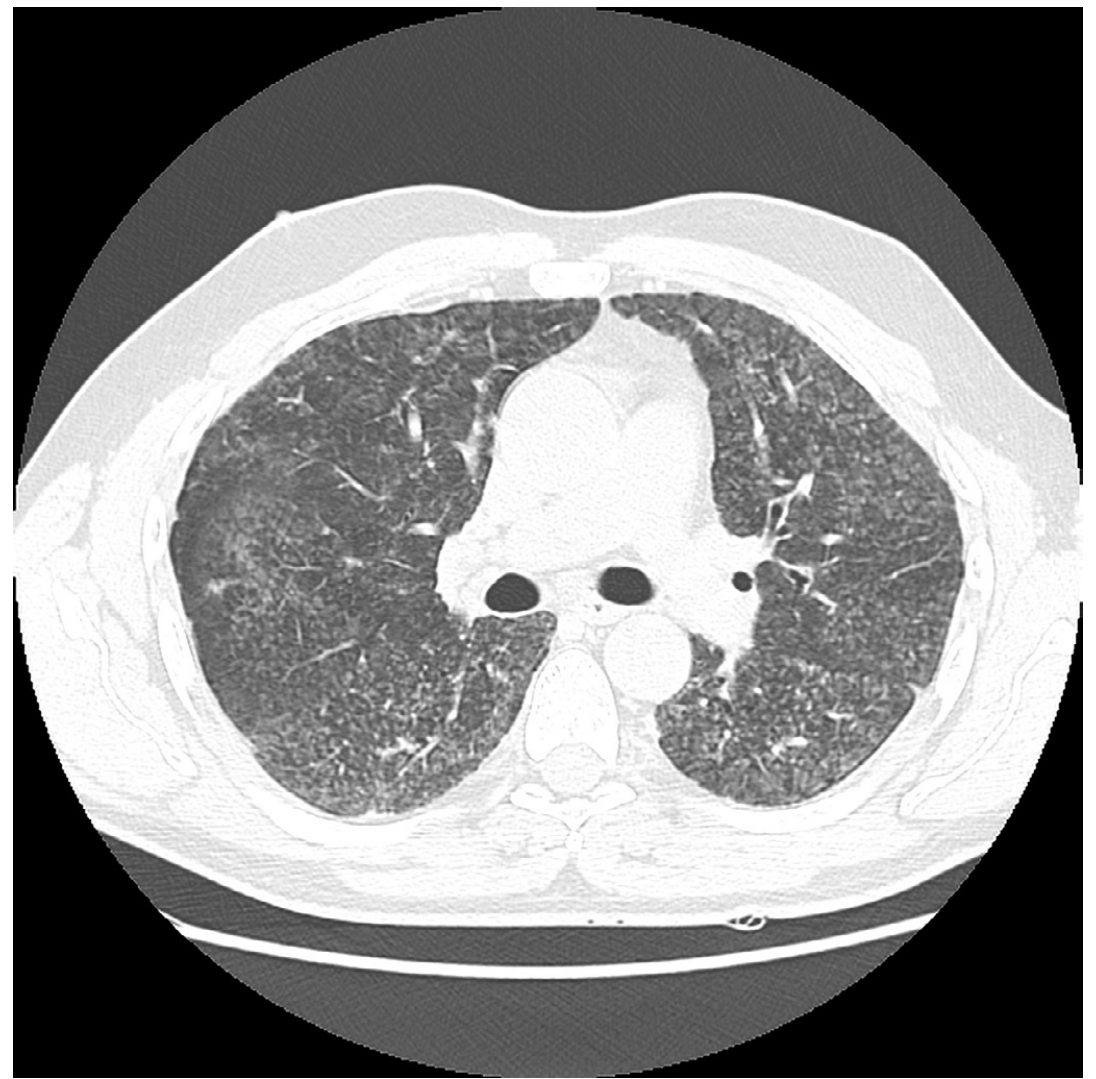

Figure 3. HRCT of patient with acute form of hypersensitivity pneumonitis (bird fancier's lung). Visible are multifocal, bilateral pulmonary nodules with the density of ground-glass. Source: Own collection, B. M.

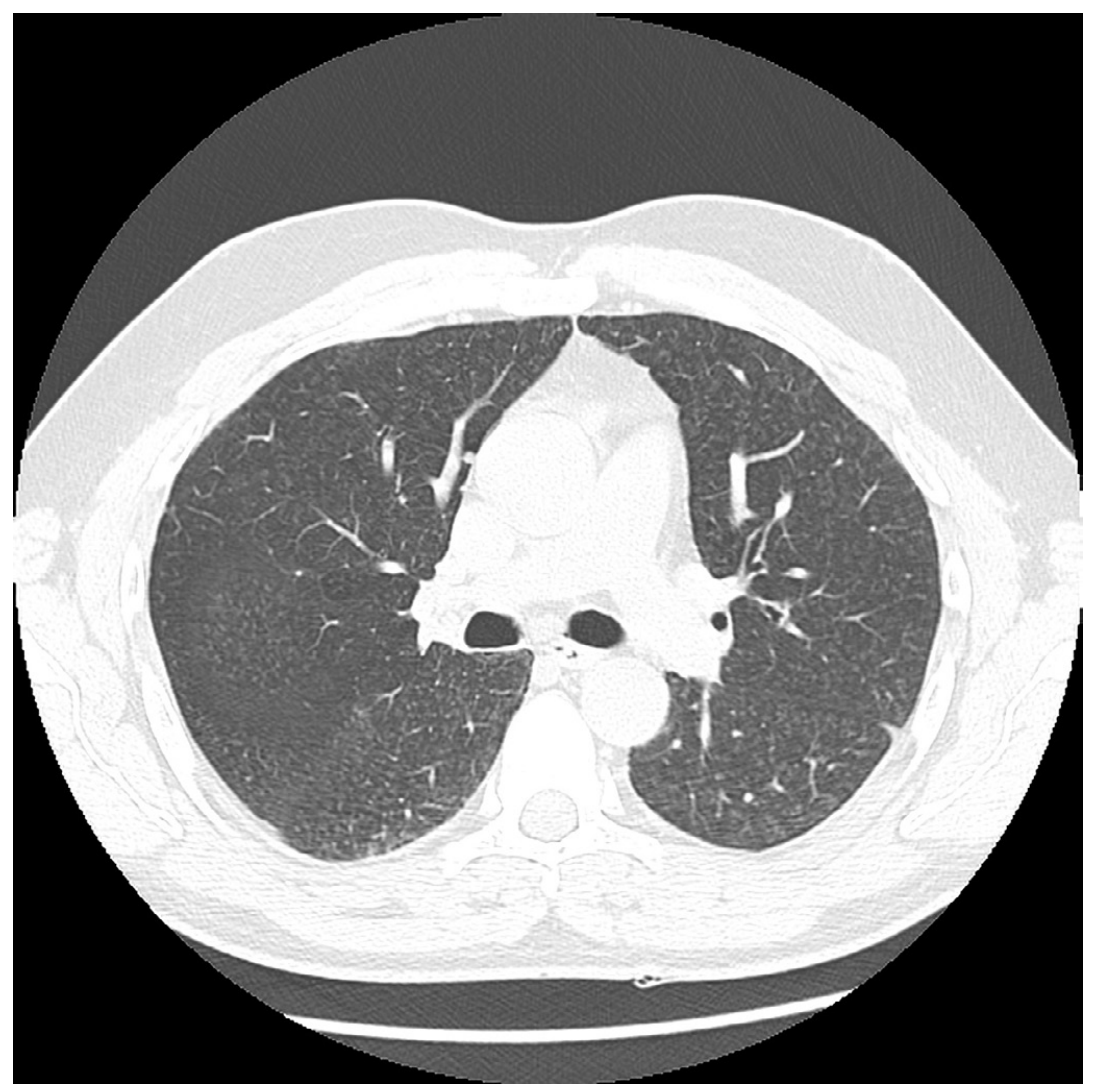

Figure 4. HRCT of the same patient with acute form of hypersensitivity pneumonitis (bird fancier's lung) 4 months after corticosteroids therapy. Almost complete regression of changes visible. Source: Own collection, B. M. 
tightness in the chest, and malaise several hours after a single, massive exposure to organic dust containing immunotoxic compounds, mostly macromolecular constituents of bacterial and/or fungal cell wall, such as LPS (endotoxin), peptidoglycan, glucans. Sometimes, in the exposed persons there were observed conjunctivitis and slight cough occurring at work, and more rarely shortness of breath, muscle pain, nausea and vomiting. These complaints are usually shortlasting and spontaneously resolve the next day or 2-3 days after. Neither X-ray nor lung function changes occur.

The pathogenesis of ODTS has not yet been sufficiently explained. Studies on the occurrence and pathogenetic mechanisms encounter difficulties, because the course of the disease is similar to that of a typical cold, often subclinical, and the majority of the affected patients do not report to a physician. The largest number of cases of ODTS were confirmed in employees engaged in swine breeding, and in workers emptying grain elevators exposed to grain dust. In contrast to the HP, the disease is recorded mostly in young persons, often in the form of group cases. The majority of researchers consider that the disease does not require any specific treatment, is short-lasting and self-curing.

To date, the remote effects of ODTS are unknown, and it is presumed that chronic bronchitis is one of them. It cannot be concluded for now how ODTS and COVID-19 may interact with each other. Undoubtedly, the course of mild forms of COVID-19 complies with the course of ODTS, and in both cases the treatment may involve only the commonly used anti-inflammatory and antipyretic drugs $[52,53]$.

\section{THERAPY}

Treatment of SARS-CoV-2 infection - applied strategies. The majority of mild COVID-19 cases do not require specific treatment other than rest, hydration and anti-inflammatory medication. It is recommended to monitor the patient's body temperature and oxygen saturation. In case of symptoms exacerbation (oxygen saturation levels < 95\%), seeking medical attention is required.

Proceedings in severe cases of COVID-19 fulfilling the ARDS criteria started with the cytokine storm and followed by multiorgan failure are problematic. Most COVID-19 causalities are caused by fulminating ARDS. At present, only symptomatic and supportive therapy is available, the same as in other severe ARDS cases.

There is no data supporting the efficacy of any specific treatment in SARS-CoV-2 infection. The effective antiviral drug should eradicate the virus during its replication phase. This is difficult because viruses replicate at a fast rate, increasing the risk of genetic mutation. The following COVID-19 treatment strategies are recommended:

- hydration;

- oxygen therapy using a nasal cannula or facial mask. Early intubation and mechanical ventilation in severe cases. Extracorporeal Membrane Oxygenation (ECMO) might be considered if available;

- empirical antibiotic therapy in the case of secondary infection;

- the use of medication approved by the Food and Drug Administration (FDA), which can be used off-label: Chloroquine and Hydroxychloroquine, administered in malaria and rheumatoid arthritis, might be effective in cytokine storm control. They should not be implemented preventively;

- antiviral medication;

- anti-inflammatory drugs, such as corticosteroids and IL-6 pathway inhibitors (Tocilizumab);

- convalescent plasma;

- immunotherapy;

- anticoagulants, such as heparin $[1,3,16,54]$.

Antiviral drugs. Remdesivir is the most promising antiviral drug for the treatment of COVID-19. It is a broad-spectrum phosphoramidate prodrug against many viral families. It works by targeting viral RNA-dependent RNA polymerase (RdRp) while evading proofreading by viral exoribonuclease, resulting in premature termination of viral RNA transcription. Early administration of Remdesivir significantly reduces viral loads and improves treatment options [55, 56, 57].

Lopinavir and Ritonavir are protease inhibitors used to treat patients with chronic human immunodeficiency caused by HIV. It has been observed that the use of these drugs in the late stage of SARS-CoV-2 infection slightly reduces mortality compared to the group of patients treated with standard medication [55]. Ribavirin and Galidesivir are used to treat hepatitis C and respiratory syncytial virus (RSV) infection. They have been proved to work against coronaviruses, but due to the reduction of haemoglobin levels, are not recommended in patients with respiratory failure in the course of COVID-19 [58]. Favipiravir was used to treat influenza resistant to Oseltamivir. Recently, preliminary results from 148 clinical trials showed the promising potency of Favipiravir in treating 149 Chinese patients with SARS-CoV-2 infection. Favipiravir was approved for treating COVID-19 in China in March 2020 [55].

Nelfinavir and Atazanavir are used to treat HIV infection. Studies have shown that they have the ability to inhibit SARS-CoV-2 replication and appear to be promising drugs for the treatment of coronavirus infection. They are currently in Phase 2 clinical trials [12]. Chloroquine and Hydroxychloroquine are administered in malaria as well as in autoimmune diseases (such as rheumatoid arthritis [RA], lupus erythematosus), and were also proposed to control the cytokine storm that occurs in critically ill late phase SARS-CoV-2 infected patients, but are not recommended in mild phase because of safety concerns $[12,55]$. Azithromycin was shown to be active in vitro against Ebola viruses, and revealed an anti-inflammatory effect. Furthermore, Azithromycin is thought to have good potential in preventing severe respiratory tract infections, and a beneficial effect of combined usage of Azithromycin and Hydroxychloroquine was observed in patients with COVID-19 [59].

Immunotherapy can be taken under consideration in SARS-CoV-2 treatment. The usage of monoclonal antibodies (mAbs), in particular, is a relatively new approach in the world of infectious diseases. Neutralizing antibodies with high specificity and a strong affinity for proteins as well as low toxicity have been used to treat viral infections caused by Ebola virus, cytomegalovirus, influenza virus, human immunodeficiency virus, and respiratory syncytial virus. The S1 domain of SARS-CoV-2 contains the RBD receptor that is used to attach the virus to the host ACE-2 receptor. Investigations were performed to identify neutralizing antibodies that target this specific region. Research is 
underway to develop a human anti-S monoclonal antibody that will cover the epitope responsible for the binding of SARS-CoV-2 to the ACE2 receptor. Perhaps we will have a drug that will not depend on possible mutations of the coronavirus, because the amino acid sequence of the ACE2 receptor does not change that quickly. It is expected that neutralizing antibodies might offer an alternative to standard COVID-19 treatment methods $[13,60]$. Tocilizumab and Sarilumab (Kevzara) are human monoclonal antibodies used in the treatment of rheumatoid arthritis, currently in clinical trials for the treatment of COVID-19 alone, or in combination with Hydroxychloroquine or Azithromycin.

Corticosteroids. Severe COVID-19 cases are dominated by an acute pneumonitis process. As in other severe viral cases of pneumonia, the host immune response is thought to play a key role in the pathophysiological effects of organ failure. Inflammatory organs injury may occur in severe COVID-19 cases. Several therapeutic interventions have been proposed to mitigate organs injury caused by inflammation in the course of viral pneumonia, among other corticosteroids. They can modulate inflammation-mediated lung injury, and thereby reduce progression to respiratory failure and death. Glucocorticoids have been widely used in syndromes closely related to COVID-19, including SARS, severe influenza, and serious pneumonia. Horby et al. [61] show that in patients hospitalized with COVID-19, the use of dexamethasone (at a dose of $6 \mathrm{mg}$ once daily) resulted in lower 28-day mortality among those who were receiving either invasive mechanical ventilation or oxygen therapy alone at randomization, but not among those receiving no respiratory support.

Methylprednisolone is a corticosteroid-based antiinflammatory drug. Wu et al. [62] reported that treatment of COVID-19 patients with methylprednisolone was shown to decrease the case-fatality risk. However, the administered dose of methylprednisolone is not specified in that investigation [62]. Despite a lack of supporting evidence, some critical care experts advocate the use of low-dose corticosteroid therapy in adults with COVID-19 and refractory shock (e.g. intravenous hydrocortisone $200 \mathrm{mg}$ per day, as a 'shockreversal' strategy) [63].

Antimicrobial agents for treating potential co-infection. The prevalence of co-infection varied among COVID-19 patients, ranging from $0 \%-50 \%$ among non-survivors. Reported co-pathogens included bacteria (such as Mycoplasma pneumoniae), yeasts (Candida species), and viruses (influenza virus, rhinovirus). Co-administration of anti-influenza and anti-bacterial medication among patients with COVID-19 pneumonia was commonly acclaimed in the light of clinical observations $[12,55,64]$.

Anticoagulant therapy. As many studies have described, severe COVID-19 is commonly complicated with coagulopathy. Disseminated intravascular coagulation (DIC) may be present in the majority of deaths. Due to virus infection and respiratory dysfunction, long-term bed rest may also increase the risk of venous thromboembolism (VTE) in severe COVID-19. Anticoagulant therapy with heparin (mainly with low molecular weight heparin) was associated with a better prognosis in severe COVID-19 patients. The 28-day mortality of heparin users was lower than that of non-users [65].
Passive immunotherapy (convalescent plasma) has been widely administered for over 100 years in treatment of measles, varicella, polio, influenza (1918), and hepatitis B. Coronavirus antibodies can be found in the convalescent blood. Their plasma is administered through transfusion to patients with severe COVID-19 who are not able to produce their own antibodies or the production of which is too slow. Many research results regarding convalescent plasma therapy efficacy have been published, but they have been unable to give unequivocal proof for the positive effect of this treatment. Ultimately, the FDA argues that the benefits of convalescent plasma treatment outweigh its risks. In the terms of no effective treatment methods, convalescent plasma usage is allowed in patients hospitalised with progressive disease symptoms [66].

Antifibrotic drugs. Pirfenidone is a novel anti-fibrotic agent with trivial adverse effects. Pirfenidone is approved for the treatment of Idiopathic Pulmonary Fibrosis (IPF) for patients with mild to moderate disease. Pirfenidone could inhibit apoptosis, downregulate ACE receptor expression, decrease inflammation, and hence protect pneumocytes and other cells from COVID-19 invasion and cytokine storm, simultaneously. Pirfenidone is also known to inhibit the production of collagen as well as fibrogenic mediators, such as TGF- $\beta$. Pirfenidone has shown promising results for SARSCoV-2 pneumonia treatment and is currently in Phase 3 clinical trials $[12,67,68]$.

Inhalation therapy with the use of human ACE-2 derived peptides. Talotta and Robertson [69] raised an idea for COVID-19 treatment by intranasal inhalation of peptides derived from the human angiotensin-converting enzyme 2 (ACE2) containing the crucial amino acid residues that interact with the S protein of SARS-CoV-2 enabling virus entry into the human host cell, displaying a similar philosophy to that presented by the designers of the anti-COVID-19 vaccines. These compounds, by competitive binding of viral glycoprotein, may prevent virus entry into target cells and also play an anti-inflammatory, anti-oxidative, anti-fibrotic, and anti-apoptotic role in epithelial and endothelial cells by antagonizing the effects of ACE2. Thus, they neutralize both SARS-CoV-2 viruses and the pro-inflammatory action of ACE, as its antagonists. Nevertheless, they must be used early, in the first phase of infection.

Treatment inhibiting the process of epithelialmesenchymal transition (EMT). A recent study [70] found EMT as a common molecular mechanism leading to fibrosis in the course of experimental HP, whereas Ochsner et al. [71] and Stewart et al. [72] demonstrated this mechanism in the course of COVID-19. These findings seem to open new possibilities in the treatment of both diseases by the use of the above-mentioned anti-fibrotic medications, such as Pirfenidone and Nintedanib, having been used so far in the cure of idiopathic pulmonary fibrosis [70].

\section{SUPPORTIVE THERAPY}

Supplementation of diet with probiotics and prebiotics. Probiotics are beneficial commensal bacteria that inhabit the human gut and other organs, and contribute to their 
microbial and immune homeostasis ('eubiosis'). Viral infections, such as COVID-19, as well as some metabolic conditions (such as diabetes, hypertension, and obesity), cause dysregulation changes in gut microbiota defined as 'dysbiosis', characterized by a decrease in microbial diversity and abundance of probiotics with a simultaneous increase in the number of opportunistic pathogens [17, 18, 73, 74]. Among the major probiotics are bacterial strains belonging to the genera Lactobacillus and Bifidobacterium, as well as to the species Faecalibacterium prausnitzii. Rajput et al. [17] and Vodnar et al. [18] report that the presence of the Faecalibacterium prausnitzii and Alistipes onderdonkii showed a negative correlation with the severity of COVID-19, while the presence of Coprobacillus, Clostridium hathewayi and Clostridium ramosum strains was positively correlated with the disease severity. According to Di Pierro [75], the K12 strain of Streptococus salivarius is a potential probiotic for the respiratory system, able to efficiently prevent lung dysbiosis and inhibit the infection with SARS-CoV-2 and other respiratory pathogens.

As about $70-80 \%$ of the human immune cells are associated with the gastrointestinal tract, close interrelations exist between the gut microbiota and immune reactions. At the state of eubiosis, immune reactions against invading viruses are observed, while at dysbiosis appear immune dysregulation and detrimental inflammatory reactions with the participations of cytokines. Along with infections, dysbiosis could also be caused by the excessive taking of medications called 'polypharmacy'. This condition occurs often in elderly persons who are therefore more prone to the SARS-CoV-2 infection [74]. This is a clear indication that in the case of COVID-19 patients, the medications of uncertain efficacy should be limited for avoiding the possible aggravation of the disease.

Between the microbiota indigenous to various human organs exist the reciprocal communication lines called 'axes'. With relation to COVID-19, the most important is the gutlung axis working in both directions. This means that gut dysbiosis causes intensive SARS-CoV-2 propagation in the lung tissue and worsening of the clinical condition of the patient. Inversely, pathologic changes caused by the virus in lung tissue may cause dysregulation of gut microbiota [74]. Similar interactions may occur in the case of other microorganisms and their products, for example, Rajput et al. [17] reported that intratracheal dosage of bacterial endotoxin (LPS) may disrupt the lung microbiota and eventually the gut microbiota. This could be interesting with regard to possible, but so far unexplored, interrelations between COVID-19 and occupational diseases caused by the inhalation of large amounts of bacterial endotoxin, such as Organic Dust Toxic Syndrome (ODTS) [8].

In conclusion, prescribing cheap, safe and efficient probiotics for COVID-19 patients represents a better alternative compared to some medications of uncertain efficacy, and may result in the improvement of the patient's condition. According to Santacroce et al. [73], most data demonstrate that probiotics can play a significant role in fighting SARSCoV-2 infection, and seem effective in lowering inflammatory status. The supplementation of probiotics are prebiotics, e.g. carbohydrate fibre-rich food including: wholegrain bread, wholegrain breakfast cereals, vegetables (such as carrots and broccoli), fruit (such as berries, pears, and oranges), legumes (peas and beans), nuts and seeds, potatoes with skin [17].
Prebiotics are utilized by the beneficial commensal bacteria (probiotics), forming the gut microbiota.

Supplementation of diet with nutraceuticals. In the current COVID-19 pandemic situation and unavailability of efficient drugs, safe alternatives like nutraceuticals can provide significant protection against the disease. It has been evidenced that dietary supplementation with high concentrations of microelements and vitamins $\mathrm{C}$ and $\mathrm{D}$ is an effective and low-cost method to intensify the immune response to COVID-19 and similar respiratory diseases. Among microelements, zinc, selenium and iron are especially efficient in boosting the immune system. The administration of nutritional supplements consisting of vitamins and minerals maintains the host health state, and because of the antioxidant properties of the supplements, the severity of viral infections is significantly diminished $[18,19]$.

The other immune-boosting factors are protein-rich foods and phytogenic feed additives (polyphenols) [19]. As it was observed that patients with COVID-19 exhibit a protein deficit, an increase in protein intake is also important for supporting the immune system [18]. In the elderly, there was also observed vitamin $\mathrm{D}$ deficiency, which increases the risk of severe COVID-19 and guts microbiota dysbiosis [74]. According to Griffin et al. [20], vitamin D deficiency in European countries significantly correlates with mortality per million from COVID-19. Thus, the authors urge European governments to recommend vitamin D supplementation at $800-1,000 \mathrm{IU} /$ day for all citizens [20]. Vodnar et al. [18] recommend that people at a higher risk (older and chronic disease-affected individuals) must abstain from unhealthy eating habits and should try to consume more unprocessed food, whole grains, vegetables, and unsaturated fats, to boost the immune system and induce protection against viral infections.

Treatment of hypersensitivity pneumonitis. Acute forms of HP tend to resolve spontaneously. In the case of severe conditions, use systemic corticosteroids for 2-4 weeks at a dose of $0.5 \mathrm{mg}$ per kilogram of weight per day, with gradual tapering-off of the dose over a period of 3 months. Treatment is carried out until the best possible improvement is achieved. Symptoms lasting longer than 6 months are permanent, and prolonged therapy has no effect. To-date, no clinical trials have been conducted on the treatment chronic form of HP. In such cases, treatment with cyclophosphamide, azathioprine or cyclosporine is tested $[10,11]$. In 2019, the results of a study evaluating the effectiveness of Nintedanib, an antifibrotic drug, in the treatment of patients with chronic hypersensitivity pneumonitis, were published, which gives hope for an improved prognosis in this group of patients $[76,77]$.

Conclusion. It should be stated that despite the numerous efforts of researchers, so far no effective COVID-19 therapy has been found. A similar situation can be noticed in chronic $\mathrm{HP}$, where only a little therapeutic effect can be observed when using corticosteroids.

It must be stressed that the excessive taking of drugs ('polypharmacy') in the situation of uncertain effects, could be detrimental, mostly for patients with the severe form of COVID-19 [73]. Thus, in individual cases, a better alternative, which is safe and cheap, could be a supportive therapy, such as supplementation of diet with probiotics, prebiotics, vitamins, and microelements $[1,3,16,17,18,19,20]$. 
COVID-19 and chronic form of hypersensitivity pneumonitis both begin with lung injury. Patients with chronic HP are at increased risk of COVID-19 mortality, compared to the general population. Perhaps the pathogenic mechanisms that lead to HP development are usually related to COVID-19 severity. Thus, it is plausible that there are shared pathogenic mechanisms between severe COVID-19 and chronic HP, which may be related to an underlying shared genetic etiology. If that was the case, it would provide some rationale for investigating whether re-purposing antifibrotic therapy could be a treatment strategy for patients with COVID-19. Ongoing clinical studies will provide the necessary evidence.

\section{PREVENTION}

Basic precautions. They are adjusted to three main modes of the SARS-CoV-2 spread:

- by long-distance ( $>2 \mathrm{~m}$ ) airborne transmission with small $(<5 \mu \mathrm{m})$ droplet nuclei, i.e. desiccated respiratory droplets suspended in the air for at least $3 \mathrm{hrs}$, and may travel distances above $10 \mathrm{~m}$;

- by short-distance $(<2 \mathrm{~m})$ airborne transmission with larger $(>5 \mu \mathrm{m})$ respiratory droplets which usually settle up to $1 \mathrm{~m}$ from the source;

- and by direct contact with infected people or contaminated surfaces $[22,78]$.

For the prevention of long-distance airborne transmission, which is very important as an occupational risk factor, filter masks and proper ventilation systems at work places and places of residence are recommended. For avoiding infection by short-distance airborne transmission, usually as the result of exposure to droplets expelled by an infected person during coughing or sneezing, filter masks are recommended for persons performing occupational duties (such as health care workers), and surgical masks for other people, as well as keeping a social distance $(2 \mathrm{~m})$ from other persons and avoiding of crowded places. For the prevention of infection by direct contact with infected people or contaminated surfaces, the best preventive measures are appropriate disinfection and frequent handwashing $[22,78,79]$. In all cases, the universal prevention measure would be efficient vaccines, available since December 2020.

Masks. Masks and respirators used for the protection of the respiratory tract against SARS-CoV-2 and other hazardous bioaerosol agents are the most important personal protective equipment (PPE) items, recommended mostly for occupationally-exposed persons. The most efficient are masks equipped with filters (filter mask), marked as 'FFP' (filtering facepiece) in the European Union classification system, and as ' $\mathrm{N}$ ' in the US National Institute for Occupational Safety and Health (NIOSH) classification system. The FFP1 mask removes $\geq 80 \%$ of airborne particles with a diameter $\geq 0.3 \mu \mathrm{m}, \mathrm{FFP} 2 \geq 94 \%$ and FFP3 $\geq 99 \%$, while N95 mask removes $\geq 95 \%$ and $\mathrm{N} 99 \geq 99 \%$ of such particles $[16,21,78,79]$.

A surgical mask is a loose-fitting, disposable device that creates a physical barrier between the mouth and nose of the wearer and potential contaminants in the immediate environment. It provides protection against large particles but not against fine aerosol. Widely worn in the living, but less in the occupational environment. Nevertheless, Dugdale and Walensky [80] recently expressed an opinion that despite much lower filtration efficiency (37-69\%) compared to N95 mask, the surgical masks are sufficient to prevent COVID-19 in the vast majority of cases.

Other Personal Protective Equipment (PPE). This equipment comprises a long-sleeved water-resistant gown for protecting the body, goggles or face shield for eye protection, and disposable rubber gloves $[23,79]$. PPE is used primarily by persons occupationally exposed to bioaerosols containing SARS-CoV-2 and/or other infectious, allergenic, and immunotoxic agents.

Ventilation. Installation of sufficient and effective ventilation should ensure full removal of the air contaminated with SARSCoV-2 or other hazardous microorganisms from occupational or indoor living spaces, and replacing it with clean air. It is important to increase the outdoor air exchange rate and to eliminate air-recirculation within the ventilation system which may lead to transmission of SARS-CoV-2, or other pathogens. Recirculation may be fully eliminated by providing $100 \%$ outside air to indoor spaces and exhausting all of it [21,22].

In hospitals, it is important to use ventilation systems generating negative pressure that allows air to flow into the isolation room (for example, the ward with COVID-19 patients, or room where infectious aerosol is generated) but not escape from the room, thereby preventing contamination $[21,23]$. The effectiveness of hospital ventilation may be enhanced by particle filtration, for example with the use of High Efficiency Particulate Air (HEPA) fibreglass filters removing at least $99.95 \%$ of particles measuring $0.3 \mu \mathrm{m}$, and by air disinfection [21].

Disinfection and sterilization. During COVID-19 pandemics, regular cleaning of surfaces, equipment, and other elements of the work environment with neutral detergent is recommended, followed by disinfection with the use of hospital disinfectants active against viruses, such as $0.1 \%$ sodium hypochlorite solution or a $70 \%$ ethanol solution $[23,79]$. If necessary, cleaning and disinfection should also be performed in the living environment. Air sterilization devices, such as ultraviolet germicidal irradiation lamps, are recommended in the work environment, mostly in hospitals, scientific laboratories, and biotechnology units $[21,79]$. In the future, disinfection methods could be improved by the use of metallic nanomaterials having antiviral properties, such as titanium dioxide and silver nanoparticles [49].

Vaccination. Effective vaccines offer the best way to protect at first the exposed workers and then a whole community against COVID-19 and against other emerging infectious diseases. There are a large number of vaccination strategies, including: RNA vaccines, DNA vaccines, protein subunit vaccines, vaccines using viral vectors, VLPs (virus-like particles) vaccines, inactivated virus vaccines and live attenuated (with lower virulence) virus vaccines [6, 81, 82, 83].

As of 2 January 2021, six anti-COVID-19 vaccines have been approved by at least one country: two mRNA-based vaccines (BNT162b2-BioNTech/Pfizer and mRNA-1273-Moderna), two non-replicating viral vector vaccines (AZD1222 and Sputnik V-Gamaleya), and two inactivated virus vaccines (BBV152-Covaxin and BBIBP-CorV-Sinopharm). 
Both mRNA-based vaccines (BNT162b2 produced by BioNTech in Germany and Pfizer in the USA, and 1273 produced by Moderna in the USA in collaboration with the National Institute of Allergy and Infectious Diseases) used viral messenger ribonucleic acid (mRNA) fragments encapsulated in lipid nanoparticles, which are able to encode Spike (S) protein of SARS-CoV-2 after injection into the human body. Immune cells from the lymph nodes process the mRNA and synthesize specific viral S protein antigen so that other immune cells recognize them and produce antibodies against it, providing anti-COVID-19 immunity [81, 83, 84]. Both vaccines showed high effectiveness exceeding $90 \%[84,85]$.

Two non-replicating viral vector vaccines (AZD1222 produced by Astra Zeneca in the UK in collaboration with Oxford University, and Sputnik V produced by Gamaleya Institute in Russia) consist of the adenoviral non-replicating vector, in which genes have been cloned using the recombinant DNA technology to produce the vaccine antigen. Adenovirus vaccine vector delivers DNA encoding the target SARSCoV-2 spike protein (the same as in the case of mRNAbased vaccines) into the human organism, causing humoral and cellular response and development of anti-COVID-19 immunity $[3,81,82,83]$.

Two inactivated virus vaccines (BBV152-Covaxin produced by Bharat Biotech in India and BBIBP-Corv produced by Sinopharm in China) used a traditional method of injecting killed viruses for raising a specific anti-SARSCoV-2 immunity in humans [83].

Since December 2020, vaccination is progressing in many countries, gradually enhancing the consciousness of safety in millions of people worldwide.

Occupational environment. The use of proper prevention measures in this environment is very important because of common outbreaks of COVID-19 in the working environment and the potential role of occupational bioaerosols in aggravating the disease. The most endangered professions are those associated with frequent contacts with other people, among whom could be infected, often symptomless persons, and those associated with exposure to various dust-borne or droplet bioaerosols [8].

Health care workers and related professions. Under the greatest hazard of infection are health care workers (HCWs) and workers of age care facilities who fulfill both the abovementioned criteria of an occupational hazard. These persons could be often exposed to droplet aerosols containing SARSCoV-2 particles, expelled by infected people at coughing and sneezing. In some high risks areas, a long-distance airborne transmission of virus attached to droplet nuclei or to other fine particles smaller than $5 \mu \mathrm{m}$ should also be considered. According to the European Centre of Disease Prevention (ECDC) recommendations for the protection of healthcare workers, HCWs providing direct care to COVID-19 patients in hospital wards or in an ambulance should wear the following PPE protecting against contact, droplet and airborne transmission: FFP2 (or N95) mask, disposable gloves, long-sleeved water-resistant gown, and goggles or face shields. When performing high-risk aerosol-generating procedures (AGP) on COVID-19 patients, such as tracheal intubation, non-invasive ventilation, tracheotomy, cardiopulmonary resuscitation, manual ventilation before intubation, oxygen administration, bronchoscopy, bronchial suctioning, sputum induction, and swabbing, HCWs should wear FFP3 (or N99) mask with other PPE, as above $[23,78,79]$. During oxygen administration, the patient should wear a surgical mask, and wear a cap during bronchoscopy [78]. AGP should be performed in a negative pressure isolation room [23].

The recommendations for the use of PPE during AGP should apply also for some other high-risk works performed by HCWs with COVID-19 patients, such as examining severely ill patients, operations or autopsies. Some works associated with exposure to viable SARS-CoV-2, or other highly infectious viruses or bacteria which are performed by HCWs, as well as by workers of scientific and diagnostic laboratories (such as the production of vaccine and/or diagnostic tests for COVID-19), require containment, sterile rooms, and biosafety or laminar cabinets, depending on the degree of hazard.

Karlsson and Fraenkel [86] expressed an optimistic opinion that providing the right PPE would ensure complete protection from COVID-19 for HCWs. They based their view on the Chinese experiences from the first stage of pandemics in Wuhan and Hefei, where providing the appropriate PPE (N95 respirators or surgical masks, protective suits, isolation gowns, gloves, face shields or goggles, hair covers, boots, and shoe covers) and adequate training in its use completely protected large groups of 420 and 426 first line HCWs from the disease, of which nobody was infected. Similarly, Dugdale and Walensky [80] positively assessed the protection of the U.S. HCWs by N95 masks during COVID-19 pandemia.

On the other hand, data from Italy suggest that healthcare workers experienced high rates of infection and death partly because of inadequate access to PPE [87]. According to Barranco and Ventura [88], over 12,680 HCWs were infected with SARS-CoV-2 in Italy from the onset of epidemic on 21 February - 7 April 2020, of whom almost 100 physicians and 26 nurses died. A major problem was access to appropriate PPE by HCWs. In some countries, there is little or no PPE (e.g. FFP2 or FFP3) [88].

Other professions. People performing other occupations requiring frequent contact with potentially infected individuals, such as transportation and post office workers, policemen and teachers, should wear surgeon masks and gloves, and whenever possible, keep a social distance (around 2 meters) from other people. Besides the healthcare sector, other sectors such as the uniformed services (e.g. police officers, firefighters), office and administrative support sectors (e.g. couriers), preschool and day-care teachers, community and social services, service and transportation workers, and even construction and extraction workers may be considered professions at risk [87].

At entering high-risk areas, for example, inhabited by infected persons, people performing 'close contact works' should wear masks equipped with filters, such as FFP-3 or N99. In some working environments with an elevated risk of infection due to possible exposure to bioaerosols containing SARS-CoV-2 particle, or other biological particles aggravating the disease (slaughterhouses, mink farms, sewage treatment plants, seafood processing plants), the workers should used filter masks while working at the sites associated with a high risk of exposure to the virus.

Taking into account that some microorganisms or substances produced by them (such as bacterial endotoxins, fungal glucans), may exacerbate the course of COVID-19, also 
in workers with symptomless or mild disease, filter masks should also be worn when performing some agricultural occupations associated with the release of large amounts of plant dusts, microorganisms and endotoxin, such as grain unloading, flax threshing or herb processing [89], despite the extremely low probability of the occurrence of the SARS-CoV-2 in such dusts. Also, some other agricultural prevention measures should be applied, such as storing grain and other plant materials at low temperature and humidity for inhibition of the development of bacteria, fungi, and mites. These organisms produce biological allergens and/or toxins evoking hypersensitivity pneumonitis (HP) or Organic Dust Toxic Syndrome (ODTS), which may exacerbate the course of COVID-19 as comorbidities of this disease. Other agricultural procedures preventing microbial growth are: storing of grain and other products in airtight silos in a $\mathrm{CO}_{2}$ atmosphere, use of grain dryers, production of less dusty haylage instead of hay, and quick harvest of crops from the field for avoiding wetting which favours the growth of microorganisms [90].

Living environment. The risk of exposure to bioaerosols containing SARS-CoV-2 or other hazardous microorganisms is much lower compared to the occupational environment, with only a few exceptions. Nevertheless, during the COVID-19 pandemic, the wearing of a surgical mask is recommended everywhere outside the home.

Precautions at governmental level. For minimizing interhuman contacts during COVID-19 pandemics and for the isolation of healthy persons from those infected (often symptomless), the country or provincial governments may decide on the total or partial 'lockdown' (closing of shops, restaurants, airports, schools, and other institutions), on the ban of gatherings, and on imposing an obligatory quarantine at home for infected persons (who do not need hospital treatment), as well as for people having contact with infected persons(s), or for those arriving from abroad.

Reduction of community air pollution. Karan et al. [91] indicated that the pollution of community air, mostly with $\mathrm{PM}_{2.5}$ (particulate matter, described also as 'dust', with diameter less than $2.5 \mu \mathrm{m}$ ), $\mathrm{NO}_{2}$ and $\mathrm{SO}_{2}$, may enhance the severity of COVID-19 by depression of the immunity, increasing host susceptibility to the infection and producing a significant pro-inflammatory state. According to Comunian et al. [92], exposure to polluting agents alters the immune response of the lung cells and induces an increase in oxidative and inflammatory stress. This cellular condition facilitates the attack of viruses and increases the severity of viral infections in exposed subjects. One of the PM mechanisms of action on cells is to trigger an inflammatory state, with the production of interleukins, such as IL-8 or IL-6, thereby predisposing to cytokine storm exacerbating the course of COVID-19. Also, the ACE2 receptor is over-expressed following exposure to $\mathrm{PM}_{2.5}$, which could additionally increase the severity of COVID-19 infection [92].

The risk was confirmed by epidemiologic data which indicate the increased COVID-19 mortality in the regions of Italy, Spain and England with the highest concentration of air pollutants [91]. The correlation between high levels of air pollution and increased numbers of COVID-19 cases has been noted also in France, the Czech Republic, and Poland [24]. Pansini and Fornacca [93], associating several annual satellite and ground indexes of air quality in China, Iran, Italy, Spain, France, Germany, United Kindom, and the USA with the COVID-19 infection, found statistically significant positive correlations between the high level of air pollution and COVID-19 infections. Similarly, Felix-Arellano et al. [94] reported that the worldwide incidence and risk of morbidity and mortality from COVID-19 increases with chronic and acute exposure to air pollution, particularly to particulate matter $\left(\mathrm{PM}_{2.5}, \mathrm{PM}_{10}\right)$ and nitrogen dioxide. Mukherjee et al. [95] expressed a view that the combined effect of both virus-laden particulate matter and gaseous pollutants can be synergistic and life-threatening, especially in highly populated areas, such as those existing in India.

In the USA, an increase of $1 \mu \mathrm{g} / \mathrm{m}^{3}$ in $\mathrm{PM}_{25}$ has been shown to increase mortality from COVID-19 by $8 \%$, and in New York state alone, by $15 \%$. In the Italian city of Bergamo, severely affected by COVID-19, SARS-CoV-2 RNA has been isolated from the airborne particulate matter, suggesting that this matter may act as a vector for transmission of COVID-19. The fine particulate matter (dust) may also contain other microbes and their toxins that may stimulate the disease, thereby acting as harmful bioaerosol. The above-mentioned facts indicate that for the prevention of COVID-19 spread, increased efforts for reducing air pollution are needed, which would also be beneficial for effectively combatting the devastating climate change $[91,95,96]$.

The positive result of the prevention measures implemented by governmental agencies, such as social lockdown and/ or quarantine isolation, was a significant reduction in air pollution, both in $\mathrm{PM}$ and gases $\left(\mathrm{NO}_{2}, \mathrm{NO}, \mathrm{CO}\right)$ by up to $30 \%$, observed in China, Italy, Spain, USA, and Brazil, and confirmed by satellite imaging [24]. The additional benefit from the application of these prevention measures and wearing masks was the decrease in the morbidity of influenza and other respiratory infections, as reported by Wu et al. [97].

In conclusion, elimination of particulate matter and smog as virus carriers, especially the most hazardous particles $\mathrm{PM}_{2.5}$, acting as carriers of droplet nuclei and microbes, is crucial for effectively combatting COVID-19 and other respiratory diseases. From the world perspective, the actions aiming to improve the global air quality by replacement of fossil fuels with renewable solar and wind energy, and reduction of industrial air pollution by installing the highefficient filters at industrial outlets, based on scrubbing technology, cyclone separation technology, electrostatic precipitation, baghouse filtering or mist separation [95], should be implemented by governing bodies, both at the national and international levels. This would certainly be beneficial for human health and the environment, as well as for mitigating the devastating climate changes.

Control of possible wastewater transmission. According to Al-Huraimel et al. [96], it is plausible that sewage could serve as vectors for SARS-CoV-2. Its RNA has been detected in the stool of symptomatic and asymptomatic COVID-19 patients, and in sewage, indicating that transmission may be possible via the raw sewage network. The authors underline the importance of wastewater surveillance for the environmental detection of COVID-19 infections [96].

Prevention of dampness and air contamination by illfunctioning devices in the living environment. Dampness in homes is often a result of water damage to buildings 
which induces excessive growth of microorganisms, mostly filamentous fungi, and following microbial corrosion. Fungi and their products are considered as causative agents of the Building-Related Disease and as factors that could potentially aggravate COVID-19 [7, 8, 98]. Remediation should include inner drying, cleaning, and disinfection [7].

Contaminated air humidifiers could be another cause of microbial air pollution in living and occupational rooms. Bacteria and fungi develop in biofilms inside humidifiers, and then are expelled into the air and inhaled by humans, causing either a specific form of HP called 'humidifier lung' or an immunotoxic disorder named 'humidifier fever', closely related to ODTS, or an acute form of byssinosis [99, 100, $101,102]$. The humidifier-related diseases usually occur in the home environment and are mostly due to exposure to contaminated ultrasonic humidifiers. Bacteria, fungi and endotoxin have been identified as causative agents of the disease $[100,101,102]$. Cases associated with occupation are reported mainly from the facilities where the production process requires elevated humidity, such as print shops [99]. Frequent cleaning of humidifiers or change of the device are recommended as prevention measures.

Ill-functioning ventilation or air-conditioning systems in various institutions, dwellings and personal cars, could also be a cause of the inhalable air contamination and subsequent respiratory disease [22, 103, 104, 105]. Kumar and Morawska [104] reported that an ill-regulated air-conditioning (A/C) system set on indoor recirculation mode, caused local outbreaks of COVID-19 in a bus and in conference rooms. Amoatey et al. [106] reported that in a hot climate zone, such as in Middle Eastern countries where the use of $\mathrm{A} / \mathrm{C}$ is necessary, ill-functioning systems are a potential cause of the disease. Besides, the indoor air temperatures of most buildings are very low due to over-consumption of air conditioning, which facilitates virus spread [106]. Morawska and Cao [103] and Morawska et al. [22], proposed an increased ventilation rate, the use of particle filtration and air disinfection, the use of natural ventilation, and avoiding air recirculation as effective precautions against the airborne transmission of the disease in the indoor environment. They postulate that these precautions should focus on the indoor environment of public places, where the risk of infection is greatest: health care facilities, shops, offices, schools, kindergartens, libraries, restaurants, elevators, cruise ships, conference rooms, and public transport $[22,103]$.

Sattar et al. [105] reported that biofilms formed in heaters/ air conditioners of personal cars, as well as those in windshield washer reservoirs and other areas of the car, may release infectious microorganisms such as Legionella pneumophila, allergenic ones such as nontuberculous mycobacteria, causing $\mathrm{HP}$, and immunotoxic microbial products such as bacterial endotoxin and/or fungal $(1 \rightarrow 3)$ - $\beta$-D-glucan.

In conclusion, moulds developing in damp houses, as well as various pathogenic microorganisms and their toxins emitted to the air by contaminated or ill-functioning humidifiers or air conditioning systems used in the living environment, should always be considered as bioaerosol components that may exacerbate the course of COVID-19, similarly as those present in the occupational environment. Prevention consists of home cleaning and disinfection, as well as the cleaning or replacement of ill-functioning devices, especially by any of the renowned HVAC (Heating, Ventilation and Air Conditioning) integrated systems.
Prevention of tobacco smoking. Tobacco smoking is one of the important risk factors of COVID-19 as a cause of many comorbidities exacerbating the course of the disease, such as chronic obstructive pulmonary disease (COPD), lung cancer and cardiovascular diseases [107]. Studies performed in recent years have shown that tobacco smoke, apart from more than 140 toxic and carcinogenic chemicals, also contains bacteria and their immunotoxic products such as endotoxin and peptidoglycan as well as fungi and their products [108]. Larsson et al. [109] found that the concentration of bacterial endotoxin (LPS) in indoor air contaminated with tobacco smoke was 120 times higher than the levels found in smokefree air. Thus, tobacco smoke may be regarded as a specific bioaerosol that contributes to some health effects of the smoke [108].

Prevention of smoking and protection of the non-smoking population (passive smokers) could be realized by the government and health care institutions, by offering help in quitting smoking, educational actions, and advertisements presenting the deadly effects of smoking, the strict prohibition of smoking in public places and working facilities, and raising the tax on tobacco products [107].

Applying air-cleaning devices in the living or occupational environment. Portable air cleaning devices (air purifiers) can limit the spread of the virus via long-range airborne particles by capturing most of those particles in a HEPA filter, and cleaning the air at a rate of up to six times per hour. Recommended are devices with a high Clean Air Delivery Rate (CADR) with metrics showing how many cubic feet of air a given air purifier effectively removes per minute. The highest possible rating scores are $450\left(11.32 \mathrm{~m}^{3}\right)$ for smoke and pollen, while $400\left(12.73 \mathrm{~m}^{3}\right)$ is the highest score for dust. Air purifiers could be an invaluable aid for existing HVAC systems [110].

Another noteworthy air cleaning aid is the cTrap, a new device for stopping or reducing potentially irritating or harmful emissions from indoor surfaces, invented by Prof. Lennart Larsson from Lund University in Sweden. This is a functional, flexible cloth consisting of an adsorbent sheet with a semipermeable barrier surrounded by two thin nonwoven layers. It may be applied directly at the source of the emissions, such as moisture-affected floors and walls, which results in an immediate stop or reduction in the emitting pollutants. It reduces about $98 \%$ of air pollutants, such as volatile organic compounds (VOCs) or mould particleassociated mycotoxins [111].

In conclusion, the presented air-cleaning devices may significantly improve the indoor air quality and decrease the risk of severe COVID-19, by removing not only SARS-CoV-2 carrying particles but also other bioaerosol components, such as bacteria, fungi and their toxins, which may enhance the severity of the disease.

\section{CONCLUSIONS}

The course of COVID-19 may be aggravated by bioaerosols containing other viruses, bacteria, and fungi, that occur mainly in the occupational environment. Accordingly, the diagnostics and treatment of COVID-19 should address such possibilities in the anamnesis, the selection of drugs, as well as recommendations for avoiding adverse exposure. 
A selection of the prevention measures against COVID-19, such as the use of a filter mask at work, maintaining wellfunctioning ventilation and air conditioning systems in the working and living environment, and the reduction of community air pollution, should also consider their effectiveness against other bioaerosols as potential diseaseaggravating agents.

\section{REFERENCES}

1. Dhama K, Khan S, Tiwari R, Sircar S, Bhat S, Malik YS, et al. Coronavirus disease 2019-COVID-19. Clin Microbiol Rev. 2020; 33(4): e00028-20. doi: 10.1128/CMR.00028-20

2. Worldometers. Coronavirus statistics. https://www.worldometers.info/ coronavirus/, last accessed on 14 February 2021.

3. Chams N, Chams S, Badran R, Shams A, Araji A, Raad M, et al. COVID-19: A multidisciplinary review. Front Public Health. 2020; 8: 383. doi: 10.3389/fpubh.2020.00383

4. Sanchez-Gonzalez MA, Moskowitz D, Issuree PD, Yatzkan G, Rizvi SA, Day K. A Pathophysiological perspective on COVID-19's lethal complication: from viremia to hypersensitivity pneumonitis-like immune dysregulation. Infect Chemother. 2020; 52: e31.

5. Lacey J, Dutkiewicz J. Bioaerosols and occupational lung disease. J Aerosol Sci. 1994; 25: 1371-1404.

6. Cox CS, Wathes CM, editors. Bioaerosols Handbook. CRC Press, 1995.

7. Górny RL, editor. Microbiological Corrosion of Buildings. A Guide to Detection, Health Hazards and Mitigation. CRC Press, Taylor \& Francis Group, Boca Raton-London-New York 2021.

8. Dutkiewicz J, Mackiewicz B, Lemieszek MK. COVID 19: Possible interrelations with respiratory comorbidities caused by occupational exposure to various hazardous bioaerosols. Part I. Occurrence, epidemiology and presumed origin of the pandemic. Ann Agric Environ Med. 2020; 27: 491-504.

9. Mackiewicz B, Dutkiewicz J, Siwiec J, Kucharczyk T, Siek E, WójcikFatla A, et al. Acute hypersensitivity pneumonitis in woodworkers caused by inhalation of birch dust contaminated with Pantoea agglomerans and Microbacterium barkeri. Ann Agric Environ Med. 2019; 26: 644-655.

10. Costabel U, Miyazaki Y, Pardo A, Koschel D, Bonella F, Spagnolo P, et al. Hypersensitivity pneumonitis. Nat Rev Dis Primers. 2020; 6: 65. doi: 10.1038/s41572-020-0191-z

11. Raghu G, Remy-Jardin M, Ryerson CJ, Myers JL, Kreuter M, Vasakova $\mathrm{M}$, et al. Diagnosis of hypersensitivity pneumonitis in adults. An official ATS/JRS/ALAT clinical practice guideline. Am J Respir Crit Care Med. 2020; 202(3): e36-e69. doi: 10.1164/rccm.202005-2032ST

12. Chilamakuri R, AgarwalS. COVID-19: Characteristics and therapeutics. Cells. 2021; 10: 206. https://doi.org/10.3390/cells10020206

13. Fouladirad S, Bach H. Development of coronavirus treatments using neutralizing antibodies. Microorganisms. 2021; 9: 165. https://doi. org/10.3390/microorganisms 9010165

14. Tarighi P, Eftekhari S, Chizari M, Sabernavaei M, Jafari D, Mirzabeigi P. A review of potential suggested drugs for coronavirus disease (COVID-19) treatment. Eur J Pharmacol. 2021; 895: 173890. doi: 10.1016/j.ejphar.2021.173890

15. Trivedi N, Verma A, Kumar D. Possible treatment and strategies for COVID-19: review and assessment. Eur Rev Med Pharmacol Sci. 2020; 24: 12593-12608.

16. Lotfi M, Hamblin MR, Rezaei N. COVID-19: Transmission, prevention, and potential therapeutic opportunities. Clinica Chimica Acta 2020; 508: 254-266.

17. Rajput S, Paliwal D, Naithani M, Kothari A, Meena1 K, Rana S. COVID-19 and gut microbiota: a potential connection. Ind J Clin Biochem. 2021; 1-12. doi: 10.1007/s12291-020-00948-9

18. Vodnar D-C, Mitrea L, Teleky B-E, Szabo K, Călinoiu L-F, Nemeş S-A, Martău G-A. Coronavirus disease (COVID-19) caused by (SARSCoV-2) infections: a real challenge for human gut microbiota. Front Cell Infect Microbiol. 2020; 10: 575559. doi: 10.3389/fcimb.2020.575559

19. Alagawany M, Attia YA, Farag MR, Elnesr SS, Nagadi SA, Shafi $\mathrm{ME}$, et al. The strategy of boosting the immune system under the COVID-19 pandemic. Front Vet Sci. 2021; 7: 570748. doi: 10.3389/ fvets. 2020.570748

20. Griffin G, Hewison M, Hopkin J, Kenny R, Quinton R, Rhodes J, et al. Vitamin D and COVID-19: evidence and recommendations for supplementation. R Soc Open Sci. 2020; 7: 201912. https://doi. org/10.1098/rsos.201912

21. Correia G, Rodrigues L, Gameiro da Silva M, Gonçalves T. Airborne route and bad use of ventilation systems as non-negligible factors in SARS-CoV-2 transmission. Med Hypotheses. 2020; 141: 109781.

22. Morawska L, Tang JW, Bahnfleth W, Bluyssend PM, Boerstrae A, Buonanno $G$, et al. How can airborne transmission of COVID-19 indoors be minimised? Environ Int. 2020; 142: 105832.

23. ECDC-European Centre for Disease Prevention and Control. Infection prevention and control for COVID-19 in healthcare settings. 2020; Available at https://www.ecdc.europa/ eu/sites/default/files/ documents/COVID-19-infectionprevention-and-control-healthcaresettings-march-2020.pdf. Accessed 3 November 2020.

24. Urrutia-Pereira M, Mello-da-Silva CA, Solé D. COVID-19 and air pollution: A dangerous association? Allergol Immunopathol (Madr). 2020; 48(5): 496-499.

25. Li H, Liu Z, Ge J. Scientific research progress of COVID-19/SARSCoV-2 in the first five months. J Cell Mol Med. 2020; 24: 6558-6570.

26. Chan KW, Wong VT, Tang SCW. COVID-19: An update on the epidemiological, clinical, preventive and therapeutic evidence and guidelines of integrative Chinese-Western Medicine for the management of 2019 novel coronavirus disease. Am J Chin Med. 2020; 48 (3): 737-762.

27. Adhikari SP, Meng S, Wu Y-J, Mao Y-P, Ye R-X, Wang Q-Z, et al. Epidemiology, causes, clinical manifestation and diagnosis, prevention and control of coronavirus disease (COVID-19) during the early outbreak period: a scoping review. Infect Dis Poverty. 2020; 9: 29. doi: 10.1186/s40249-020-00646-x

28. Cascella M, Rajnik M, Cuomo A, Dulebohn SC, Di Napoli R. Features, evaluation and treatment of Coronavirus (COVID-19). In: StatPearls (Internet), Treasure Island (FL), StatPearls Publishing 2020. PMID: 32150360.

29. Chen N, Zhou M, Dong X, Qu J, Gong F, Han Y. Epidemiological and clinical characteristics of 99 cases of 2019 novel coronavirus pneumonia in Wuhan, China: a descriptive study. Lancet. 2020; 395: 507-513.

30. Lake MA. What we know so far: COVID-19 current clinical knowledge and research. Clin Med (Lond). 2020; 20: 124-127.

31. Wu Z, McGoogan JM. Characteristics of and important lessons from the coronavirus disease 2019 (COVID-19) outbreak in China: summary of a report of 72,314 cases from the Chinese Center for Disease Control and Prevention. JAMA 2020; 323: 1239-1242.

32. Williamson EJ, Walker AJ, Bhaskaran K, Bacon S, Bates C, Mortin $\mathrm{CE}$, et al. Factors associated with COVID-19-related death using OpenSAFELY. Nature. 2020; 584: 430-436.

33. Berlin DA, Gulick RM, Martinez FJ. Severe Covid-19. N Engl J Med. 2020; 383: 2451-2460.

34. Varga Z, Flammer AJ, Steiger P, Haberecker M, Andermatt R, Zinkernagel A, et al. Endothelial cell infection and endotheliitis in COVID-19. Lancet. 2020; 395: 1417-1418.

35. Marin BG, Aghagoli G, Lavine K, Yang L, Siff EJ, Chiang SS, et al. Predictors of COVID-19 severity: A literature review. Rev Med Virol. 2021, 31(1): 1-10, 2146. doi: 10.1002/rmv.2146

36. Song YG, Shin HS. COVID-19, a clinical syndrome manifesting as hypersensitivity pneumonitis. Infect Chemother. 2020; 52: 110-112.

37. Creamer AW, Barratt SL. Prognostic factors in chronic hypersensitivity pneumonitis. Eur Respir Rev. 2020 29: 190167. doi: 10.1183/16000617.0167-2019

38. Ohtsuka Y, Munakata M, Tanimura K, Ukita H, Kusaka H, Masaki Y, et al. Smoking promotes insidious and chronic farmer's lung disease, and deteriorates the clinical outcome. Intern Med. 1995; 34: 966-971.

39. Bellanger AP, Reboux G. Studying smoking benefit in farmer's lung to understand Covid-19. Occup Med (Lond). 2020; 12, 70: 620-621.

40. Propper RE. Does cigarette smoking protect against SARS-CoV-2 infection? Nicotine Tob Res. 2020; 22: 1666. doi: 10.1093/ntr/ntaa073

41. Erdem Ö, Derin E, Sagdic K, Yilmaz EG, Inci F. Smart materialsintegrated sensor technologies for COVID-19 diagnosis. Emergent Mater. 2021; 1-17. doi: 10.1007/s42247-020-00150-w

42. Cleverley J, Piper J, Jones MM. The role of chest radiography in confirming covid-19 pneumonia. BMJ. 2020; 370: m2426. doi: 10.1136/ bmj.m 2426

43. Ai T, Yang Z, Hou H, Zhan C, Chen C, Lv W, et al. Correlation of chest CT and RT-PCR testing for Coronavirus Disease 2019 (COVID-19) in China: a report of 1014 cases. Radiology. 2020; 296: E32-E40. doi: 10.1148/radiol.2020200642

44. Zhang J, Zhou L, Yang Y, Peng W, Wang W, Chen X. Therapeutic and triage strategies for 2019 novel coronavirus disease in fever 
clinics. Lancet Respir Med. 2020; 8(3): el1-el2. doi: 10.1016/S22132600(20)30071-0

45. Guan WJ, Ni ZY, Hu Y, Lang WH, Ou CQ, He JX, et al. China Medical Treatment Expert Group for Covid-19. Clinical Characteristics of Coronavirus Disease 2019 in China. N Engl J Med. 2020; 382: 17081720 .

46. Huang C, Wang Y, Li X, Ren L, Zhao J, Hu Y, et al. Clinical features of patients infected with 2019 novel coronavirus in Wuhan, China. Lancet. 2020; 395: 497-506.

47. Li Y, Xia L. Coronavirus Disease 2019 (COVID-19): Role of chest CT in diagnosis and management. Am J Roentgenol. 2020; 214: 1280-1286.

48. Huang Y, Wang S, Liu Y, Zhang Y, Zheng C, Zheng Y, et al. A preliminary study on the ultrasonic manifestations of peripulmonary lesions of non-critical novel coronavirus pneumonia (COVID-19). SSRN. 2020. doi: $10.21203 / \mathrm{rs} .2 .24369 / \mathrm{vl}$

49. Campos EVR, Pereira AES, De Oliveira JL, Carvalho LB, GuilgerCasagrande M, De Lima R, Fraceto LF. How can nanotechnology help to combat COVID-19? Opportunities and urgent need. J Nanobiotechnol. 2020; 18: 125. https://doi.org/10.1186/s12951-020-00685-4

50. Acquah C, Jeevanandam J, Tan KX, Danquah MK. Engineered aptamers for enhanced COVID-19 theranostics. Cell Mol Bioeng. 2021; 1-13. doi: 10.1007/s12195-020-00664-7

51. Silva CI, Churg A, Müller NL. Hypersensitivity pneumonitis: spectrum of high-resolution CT and pathologic findings. Am J Roentgenol. 2007; 188: 334-344.

52. Emmanuel DA, Wenzel FJ, Lawton BR. Pulmonary mycotoxicosis. Chest. 1975; 67: 293-297.

53. Seifert SA, Von Essen S, Jacobitz K, Crouch R, Lintner CP. Organic Dust Toxic Syndrome: a review. J Toxicol Clin Toxicol. 2003; 41: 185-193.

54. Shazia J, Nick M, Graham C, Dela Cruz CS, Gross JE, Pasnick S. Diagnosis and management of COVID-19 disease. Am J Respir Crit Care Med. 2020; 201: P19-P22.

55. Jean S-S, Lee P-I, Hsueh P-R. Treatment options for COVID-19: The reality and challenges. J Microbiol Immunol Infect. 2020; 54: 436-443.

56. Agostini ML, Andres EL, Sims AC, Graham RL, Sheahan TP, Lu X, et al. Coronavirus susceptibility to the antiviral remdesivir (GS5734 ) is mediated by the viral polymerase and the proofreading exoribonuclease. 2018; mBio 9: e00221-18. https://doi.org/10.1128/ mBio.00221-18

57. Beigel JH, Tomashek KM, Dodd LE, Mehta AK, Zingman BS, Kalil AC, et al. Remdesivir for the treatment of COVID-19 - final report. N Engl J Med. 2020; 383: 1813-1826.

58. Martinez MA. Compounds with therapeutic potential against novel 480 respiratory 2019 coronavirus. Antimicrob Agents Chemother. 2020; 64: e00399-20. https://doi.org/10.1128/AAC.00399-20

59. Stebbing J, Phelan A, Griffin I, Tucker C, Oechsle O, Smith D, Richardson P. COVID-19: combining antiviral and anti-inflammatory treatments. Lancet Infect Dis. 2020; 20: 400-402.

60. Shah M, Ahmad B, Choi S, Woo HG. Mutations in the SARS-CoV-2 spike RBD are responsible for stronger ACE2 binding and poor antiSARS-CoV mAbs cross-neutralization. Comput Struct Biotechnol J. 2020: 18: 3402-3414.

61. Horby P, Lim WS, Emberson JR, Mafham M, Bell JL, Linsell L, et al. Dexamethasone in hospitalized patients with Covid-19 preliminary report. N Engl J Med. 2020; NEJMoa2021436. doi: 10.1056/ NEJMoa2021436

62. Wu C, Chen X, Cai Y, Xia J, Zhou X, Xu S, et al. Risk factors associated with acute respiratory distress syndrome and death in patients with coronavirus disease 2019 pneumonia in Wuhan, China. JAMA Intern Med. 2020; 180: 934-943.

63. Mehta P, McAuley DF, Brown M, Sanchez E, Tattersall RS, Manson JJ. COVID-19: consider cytokine storm syndromes and immunosuppression. Lancet. 2020; 395: 1033-1034.

64. Kalil AC, Patterson TF, Mehta AK, Tomashek KM, Wolfe CR, Ghazaryan V, et al. Baricitinib plus Remdesivir for hospitalized adults with COVID-19. N Engl J Med. 2020; doi: 10.1056/NEJMoa2031994

65. Tang N, Bai H, Chen X, Gong J, Li D, Sun Z. Anticoagulant treatment is associated with decreased mortality in severe coronavirus disease 2019 patients with coagulopathy. J Thromb Haemost. 2020; 18: 1094-1099.

66. Katz LM. (A little) clarity on convalescent plasma for Covid-19. N Engl J Med. 2021. https://doi.org/10.1056/NEJMe2035678

67. Seifirad S. Pirfenidone: A novel hypothetical treatment for COVID-19. Med Hypotheses. 2020; 144:110005. doi: 10.1016/j.mehy.2020.110005

68. Tzilas V, Tzouvelekis A, Bouros B, et al. Antifibrotic treatment in 18 patients with chronic hypersensitivity pneumonitis. Eur Respir J. 2019; 54: PA4733.
69. Talotta R, Roberston ES. Perspectives: potential therapeutic approach with inhalation of ACE2-derived peptides for SARS-CoV-2 infection. Am J Clin Exp Immunol. 2020; 9(5): 73-80.

70. Lemieszek MK, Rzeski W, Golec M, Mackiewicz B, Zwoliński J, Dutkiewicz J, Milanowski J. Pantoea agglomerans chronic exposure induces epithelial-mesenchymal transition in human lung epithelial cells and mice lungs. Ecotoxicol Environ Saf. 2020; 194: 110416.

71. Ochsner SA, Pillich RT, McKenna NJ. A transcriptional regulatory atlas of coronavirus infection of human cells. BioRxiv. 2020; 2020.04.24.059527. doi: 10.1101/2020.04.24.059527

72. Stewart CA, Gay CM, Ramkumar K, Cargill KR, Cardnell RJ, Nilsson $\mathrm{MB}$, et al. SARS-CoV-2 infection induces EMT-like molecular changes, including ZEB1-mediated repression of the viral receptor ACE2, in lung cancer models. BioRxiv. 2020; 2020.05.28.122291. doi: 10.1101/2020.05.28.122291

73. Santacroce L, Inchingolo F, Topi S, Del Prete R, Di Cosola M, Charitos IA, Montagnani M. Potential beneficial role of probiotics on the outcome of COVID-19 patients: An evolving perspective. Diabetes Metab Syndr. 2021; 15: 295-301. doi: 10.1016/j.dsx.2020.12.040

74. Donati Zeppa S, Agostini D, Piccoli G, Stocchi V, Sestili P. Gut microbiota status in COVID-19: An unrecognized player? Front Cell Infect Microbiol. 2020; 10: 576551. doi: 10.3389/fcimb.2020.576551

75. Di Pierro F. A possible probiotic (S. salivarius K12) approach to improve oral and lung microbiotas and raise defenses against SARSCoV-2. Minerva Med. 2020; 111: 281-283. doi: 10.23736/s00264806.20.06570-2.

76. Distler O, Highland KB, Gahlemann M, Azuma A, Fischer A, Mayes $\mathrm{MD}$, et al. Nintedanib for systemic sclerosis-associated interstitial lung disease. N Engl J Med. 2019; 380: 2518-2528.

77. Flaherty KR, Wells AU, Cottin V, Devaraj A, Walsh SLF, Inoue Y, et al. Nintedanib in progressive fibrosing interstitial lung diseases. N Engl J Med. 2019; 381: 1718-1727.

78. Ferioli M, Cisternino C, Leo V, Pisani L, Palance P, Nava S. Protecting healthcare workers from SARS-CoV-2 infection: practical indications. Eur Respir Rev. 2020; 29: 200068. https://doi. org/10.1183/16000617.0068-2020

79. Spinazzè A, Cattaneo A, Cavallo DM. COVID-19 outbreak in Italy: protecting worker health and the response of the Italian Industrial Hygienists Association. Ann Work Expo Health. 2020; 64: 559-564. doi: 10.1093/annweh/wxaa044

80. Dugdale CM, Walensky RP. Filtration efficiency, effectiveness, and availability of N95 face masks for COVID-19 prevention. JAMA Intern Med. 2020. doi: 10.1001/jamainternmed.2020.4218. Aug 11.

81. Calina D, Docea AO, Petrakis D, Egorov AM, Ishmukhametov AA, Gabibov AG, et al. Towards effective COVID 19 vaccines: Updates, perspectives and challenges (Review). Int J Mol Med. 2020; 46: 3-16. doi: 10.3892/ijmm.2020.4596

82. Kandimalla R, John A, Abburi C, Vallamkondu J, Reddy PH. Current status of multiple drug molecules, and vaccines: an update in SARSCoV-2 therapeutics. Mol Neurobiol. 2020; 57: 4106-4116.

83. Scarabel L, Guardascione M, Dal Bo M, Toffoli G. Pharmacological strategies to prevent SARS-CoV-2 infection and treat the early phases of COVID-19. Int J Infect Dis. 2021; 104: 441-451.

84. Herper M. Covid-19 vaccine from Pfizer and BioNTech is strongly effective, early data from large trial indicate. STAT, November 9 , 2020. https://www.statnews.com/2020/11/09/covid-19-vaccine-frompfizer-and-biontech-is-strongly-effective-early-data-from-large-trialindicate/

85. Zimmer C. Moderna's Covid Vaccine: What You Need to Know. The New York Times, 11 November 2020.

86. Karlsson U, Fraenkel C-J. Complete protection from covid-19 is possible for health workers. All they need is the right protective equipment. BMJ. 2020; 370: m2641. http://dx.doi.org/10.1136/bmj.m2641

87. Godderis L, Boone A, Bakusic J. COVID-19: a new work-related disease threatening healthcare workers. Occup Med. 2020; 70: 315-316.

88. Barranco R, Ventura F. Covid-19 and infection in health-care workers: An emerging problem. Medico-Legal J. 2020; 88: 65-66.

89. Mackiewicz B, Skórska C, Dutkiewicz J. Relationship between concentrations of microbiological agents in the air of agricultural settings and occurrence of work-related symptoms in exposed persons. Ann Agric Environ Med. 2015; 22: 473-477.

90. Dutkiewicz J, Skórska C, Mackiewicz B, Cholewa G. Prevention of the Diseases Caused by Organic dusts in the Agriculture and Agricultural Industry. Institute of Rural Health, Lublin 2000 (in Polish).

91. Karan A, Ali K, Teelucksingh S, Sakhamuri S. The impact of air pollution on the incidence and mortality of COVID-19. Glob Health Res Policy. 2020; 5: 39. https://doi.org/10.1186/s41256-020-00167-y 
92. Comunian S, Dongo D, Milani C, Palestini P. Air pollution and COVID-19: The role of particulate matter in the spread and increase of COVID-19's morbidity and mortality. Int J Environ Res Public Health. 2020; 17: 4487. doi: 10.3390/ijerph17124487

93. Pansini R, Fornacca D. Initial evidence of higher morbidity and mortality due to SARS-CoV-2 in regions with lower air quality. MedRxiv. 2020; https://www.medrxiv.org/content/10.1101/2020.04.04

94. Félix-Arellano EE, Schilmann A, Hurtado-Díaz M, Texcalac-Sangrado JL, Riojas-Rodríguez H. Quick review: air pollution and morbimortality by Covid-19. Salud Publica Mex. 2020; 62: 582-589 (in Spanish)

95. Mukherjee S, Boral S, Siddiqi H, Mishra A, Meikap BC. Present cum future of SARS-CoV-2 virus and its associated control of virus-laden air pollutants leading to potential environmental threat - a review. J Environ Chem Eng. 2021; 9: 104973. doi: 10.1016/j.jece.2020.104973

96. Al Huraimel K, Alhosani M, Kunhabdulla S, Stietiya MH. SARS$\mathrm{CoV}-2$ in the environment: Modes of transmission, early detection and potential role of pollutions. Sci Total Environ. 2020; 744: 140946.

97. Wu D, Lu J, Liu Y, Hang Z, Luo L. Positive effects of COVID-19 control measures on influenza prevention. Int J Infect Dis. 2020; 95: 345-346.

98. Samson RA, Flannigan B, Flannigan ME, et al. Health Implications of Fungi in Indoor Environments. Elsevier, Amsterdam 1994.

99. Anderson K, Watt AD, Sinclair D, Lewis C, McSharry CP, Boyd G. Climate, intermittent humidification, and humidifier fever. Br J Ind Med.1989; 46: 671-674.

100. Ando A, Hagiya H, Nada T, Kiura K, Waseda K, Kammei Rai K, et al. Hypersensitivity pneumonitis caused by a home ultrasonic humidifier contaminated with Candida guilliermondii. Intern Med. 2017; 56: 3109-3112.

101. Ohnishi H, Yokoyama A, Hamada H, Manabe S, Ito R, Watanabe A et al. Humidifier lung: Possible contribution of endotoxin-induced lung injury. Intern Med. 2002; 41: 1179-1182.
102. Müller-Wening D, Koschel D, Stark W, Sennekamp H-J. Humidifierassociated disease in the general population. Dtsch Med Wochenschr. 2006; 131: 491-496 (in German).

103. Morawska L, Cao J. Airborne transmission of SARS-CoV-2: the world should face the reality. Environ Int. 2020; 139: 105730.

104. Kumar P, Morawska L. Could fighting airborne transmission be the next line of defence against COVID-19 spread? City Environ Interact. 2019; 4: 100033.

105. Sattar SA, Wright KE, Zargar B, Rubino JR, Iljaz MK. Airborne infectious agents and other pollutants in automobiles for domestic use: potential health impacts and approaches to risk mitigation. J Environ Public Health. 2016; 2016: 1548326. doi: 10.1155/2016/1548326

106. Amoatey P, Omidvarborna H, Baawain MS, Al-Mamun A. Impact of building ventilation systems and habitual indoor incense burning on SARS-CoV-2 virus transmissions in Middle Eastern countries. Sci Total Environ. 2020; 733: 139356.

107. WHO Report on the Global Tobacco Epidemic, 2008: The MPOWER Package. World Health Organization, Geneva 2008.

108. Larsson L, Szponar B, Ridha B, Pehrson C, Dutkiewicz J, KrysińskaTraczyk E, Sitkowska J. Identification of bacterial and fungal components in tobacco and tobacco smoke. Tob Induc Dis. 2008; Epub 4:4. doi: 10.1 186/1617-9625-4-4. http:||www.tobaccoinduceddiseases. com/content $/ 4 / 1 / 4$

109. Larsson L, Szponar B, Pehrson C. Tobacco smoking increases dramatically air concentrations of endotoxin. Indoor Air. 2004; 14: 421-424.

110. Mulrooney Eldred S. Coronavirus FAQ: Is it a good idea to buy an air cleaner for my home? NPR., September 4, 2020. https://www. npr.org/sections/goatsandsoda/2020/09/04/908896132/coronavirusfaq-is-it-a-good-idea-to-buy-an-air-cleaner-for-my-home (accessed November 14, 2020).

111. Markowicz P, Larsson L. The surface emissions trap: a new approach in indoor air purification. J Microbiol Methods. 2012; 91: 290-294. 